\title{
Responses of Neurons in the Parietal and Temporal Visual Pathways during a Motion Task
}

\author{
Vincent P. Ferrera, Kirsten K. Rudolph, and John H. R. Maunsella \\ Department of Physiology and Center for Visual Science, University of Rochester, Rochester, New York 14642
}

The visual cortex of macaque monkeys has been divided into two functional streams that have been characterized in terms of sensory processing (color/form vs motion) and in terms of behavioral goals (object recognition vs spatial orientation). As a step toward unifying these two views of cortical processing, we compared the behavioral modulation of sensory signals across the two streams in monkeys trained to do a visual short-term memory task. We recorded from individual neurons in areas MT, MST, $7 \mathrm{a}$, and V4 while monkeys performed a delayed match-to-sample task using direction of motion as the matching criterion. This task allowed us to determine if sensory responses were modulated by extraretinal signals related to the direction of the remembered sample. We sorted neuronal responses as a function of the remembered direction and calculated a modulation index, $\mathrm{MI}=$ (maximum response - minimum response)/ (maximum response + minimum response). In the motion pathway, we found virtually no extraretinal signals in MT (average $\mathrm{MI}=0.11 \pm 0.01 \mathrm{SE}, 66$ cells), but progressively stronger extraretinal signals in later stages, that is, MST (average $\mathrm{MI}=\mathbf{0 . 1 7} \pm \mathbf{0 . 0 1} \mathrm{SE}, 57$ cells) and 7 a (average $\mathrm{MI}$ $=0.23 \pm 0.02 \mathrm{SE}, 46$ cells). In contrast to MT, strong extraretinal signals for direction matching were found in $V_{4}$ (average $\mathrm{MI}=0.28 \pm 0.02 \mathrm{SE}, 94$ cells), a relatively early stage of the color/form pathway, even though this pathway is not generally viewed as playing a major role in motion processing. Some cells in V4 were also tested while the animals performed a color matching task. These cells showed memory-related modulation of their response when either color or direction was used as the matching criterion. We conclude that extraretinal signals related to the match-tosample task may be stronger in the temporal (color/form) pathway than in the parietal (motion) pathway, regardless of the stimulus dimension involved. Furthermore, our results indicate that the temporal pathway is capable of making a significant contribution to motion processing in tasks where

Received Nov. 11, 1993; revised Mar. 25, 1994; accepted Apr. 13, 1994.

We thank J. A. Movshon for advice regarding the ROC analysis, P. Vamvakias for valuable technical assistance, and J. Assad, J. Cummings, S. du Lac, M. Kahlon, S. Lisberger, H. Mahncke, J. Raymond, Y. Selig, and A. Sereno for comments on the manuscript. This work was supported by NIH Fellowship NS08658 and ONR N00014-90-5-1070.

Correspondence should be addressed to Vincent P. Ferrera, Department of Physiology, P.O. Box 0444, University of California at San Francisco, San Francisco, CA 94143.

${ }^{a}$ Present address: Division of Neuroscience, Baylor College of Medicine, One Baylor Plaza, S603, Houston, TX 77030.

Copyright (C) 1994 Society for Neuroscience 0270-6474/94/146171-16\$05.00/0 motion can be considered as a cue for the identification of object attributes.

[Key words: macaque, cortex, extrastriate, parietal, temporal, motion, single unit, extraretinal]

It has been firmly established that the visual cortex of primates contains two major functional streams, one of which goes through the visual areas of the parietal lobe, and the other, those of the temporal lobe (Ungerleider and Mishkin, 1982). These two streams have been characterized in terms of their sensory response properties and also in terms of their roles with respect to different classes of visual behavior. A component of the occipitoparietal stream (hereafter, simply "parietal") comprising areas MT and MST is often referred to as the motion pathway due to its high proportion of direction-selective neurons (Zeki, 1978; Maunsell and Van Essen, 1983; Albright, 1984). The occipitotemporal stream (hereafter, "temporal") is referred to as the color and form pathway; it has a higher degree of chromatic sensitivity (Zeki, 1978; Tanaka et al., 1986; Schein and Desimone, 1990) and neurons there have been found to be selective for complex shapes and patterns (Gross et al., 1972; Desimone et al., 1985; Desimone and Schein, 1987). The two streams have also been described in terms of the kinds of behavioral tasks that each supports. The temporal stream is thought to be involved in visual short-term memory (Fuster and Jervey, 1981; Miyashita and Chang, 1988) and object recognition, while the parietal stream is thought to play a role in spatial orientation and visually guided movement (see Andersen, 1987; Goodale and Milner, 1992).

In characterizing the functions of the two pathways, it is useful to distinguish between signals that are related to the physical properties of the retinal stimulus and "extraretinal" signals that convey information regarding its behavioral context. Within a given area, these two sets of signals are often related, such that both the stimulus selectivities and the extraretinal signals that are seen in a particular pathway appear tailored to the role of that pathway in behavior. Thus, for tasks such as navigating through a complex environment or tracking a moving target, motion information carried by the parietal pathway is necessary for analyzing optic flow patterns or computing target trajectories. In order to recognize objects, on the other hand, the temporal pathway needs to analyze color, form, and position information; motion is less relevant. In the motion pathway, extraretinal signals have been found while animals are performing smooth pursuit (Newsome et al., 1988) or saccadic eye movement tasks (Andersen and Mountcastle, 1983; Duhamel et al., 1992), and also in spatial memory tasks (Andersen et al., 1990; 


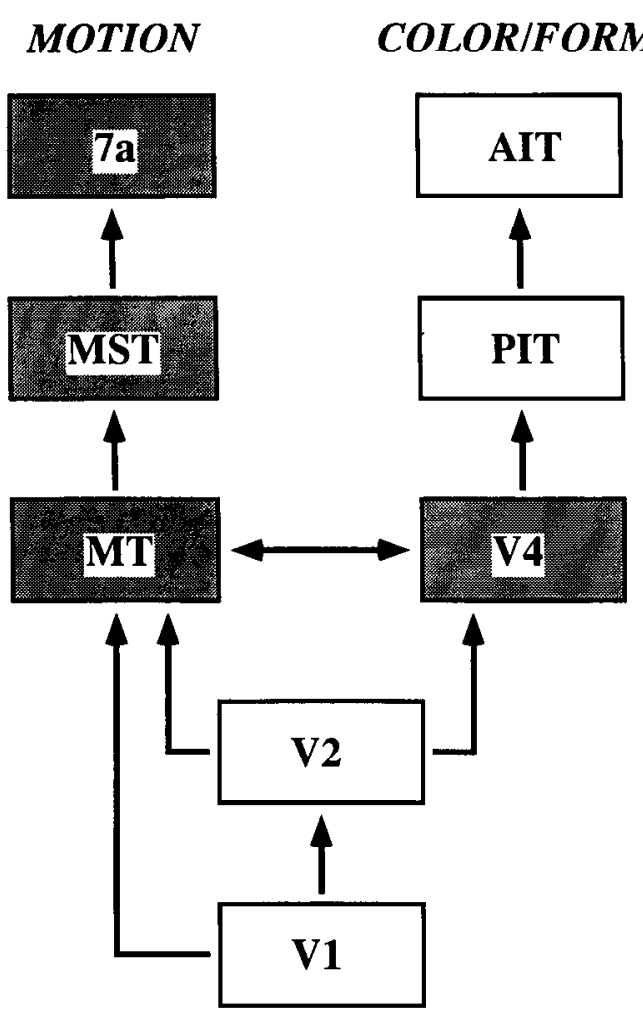

Figure 1. A highly reduced version of the hierarchy of visual cortical areas. Only a few of the $\mathbf{3 0}$ or more different areas and hundreds of connections are shown. On the left are the parietal areas comprising the "motion" pathway, and on the right are temporal areas included in the "color/form" pathway. The areas are also arranged according to their hierarchical position within each pathway. The shaded boxes represent the areas that were examined in the present study.

Steinmetz et al., 1992). In the color/form pathway, extraretinal signals have been found in short-term memory and selective attention tasks using color and orientation (Fuster and Jervey, 1981; Moran and Desimone, 1985; Haenny et al., 1988; Miyashita and Chang, 1988; Spitzer et al., 1988; Maunsell et al., 1991; Miller et al., 1993).

However, the relationship between sensory processing and behavior needs further clarification, particularly with regard to the role of motion processing in tasks that involve the classification and identification of objects or object attributes. In some cases, motion may simply interfere with object recognition by degrading visual acuity, but there are other cases in which it is possible to recognize two- and three-dimensional shapes solely on the basis of motion information. Such is the case in the recovery of three-dimensional structure-from-motion and motion-defined forms. Furthermore, there is the compelling phenomenon of biological motion in which points of light moving in a characteristic manner are seen unambiguously as a person walking (Johansson, 1973; Hoffman and Flinchbaugh, 1982). At more abstract levels, motion input is often necessary for interpreting the actions and intentions of other organisms (Perrett et al., 1989). One can therefore make a strong argument that characteristic patterns of motion contribute to the identification of features and objects.

One objective of this study was to devise a task whose behavioral requirements, that is, short-term memory and feature identification, were suited to the temporal pathway, but which used a set of stimuli, moving random dots, that were tailored to the response properties of the parietal pathway. How would such a task engage neuronal responses in the two pathways? Would it reveal extraretinal signals of cognitive value for feature identification in the parietal pathway, or would the behavioral requirements of the task draw on the capabilities of the temporal pathway, despite its relative inferiority in motion processing? We tested these possibilities by training monkeys to perform a match-to-sample task where the attribute to be matched was the direction of motion of a field of dynamic random dots undergoing uniform translation. We chose the match-to-sample task because it has been used previously to demonstrate taskspecific extraretinal signals in the temporal pathway (Fuster and Jervey, 1981; Haenny et al., 1988; Maunsell et al., 1991). We refer to this as a feature identification task because it seems unlikely that the stimuli were sufficiently complex to qualify as "objects," as the term is commonly used.

We recorded from three areas in the parietal pathway, MT, MST, and 7a, and area V4 in the temporal pathway. We were therefore able to compare stimulus- and task-specific signals at different hierarchical levels of the parietal pathway (MT, MST, and $7 \mathrm{a}$ ), and also to make comparisons between areas at the same level across the parietal and temporal pathways (MT and V4). A highly reduced version of the visual cortical hierarchy (Felleman and Van Essen, 1991) is shown in Figure 1 to illustrate the hierarchical relationships of the areas examined in the present study (gray boxes) and some of their connections.

In the match-to-sample task we used, monkeys were presented with a sequence of random dot stimuli moving in different directions, and they were required to compare the direction of each stimulus with that of a previously seen cue or "sample." This allowed us to measure neuronal response as a function of stimulus direction (i.e., conventional stimulus selectivity), and also as a function of cue direction. Since the cue is never present when we collect the cell's responses, any cell whose response is consistently modulated by cue direction is considered to be carrying an extraretinal signal. Such signals provide information about the behavioral context in which the stimuli are seen, namely, what direction the animal is seeking to match on each trial, and this information can be quantified in the same manner as the cell's conventional stimulus selectivity. Using this task, we found that extraretinal signals for cue direction, measured as percentage modulation of a cell's total response, were weak in area MT, but grew progressively stronger at higher stages of the motion pathway (MST and 7a). Somewhat surprisingly, the strongest signals for cue direction were found in area V4. Analyses of statistical reliability (Tolhurst et al., 1983) showed that some neurons in MT and other parietal areas can provide information about cue direction. However, the most highly reliable signals for cue direction were found in V4.

Some of these results have been reported in abstract form (Ferrera and Maunsell, 1992).

\section{Materials and Methods \\ Behavioral tasks}

We recorded from individual neurons in visual areas MT, MST, 7a, and V4 in four hemispheres of two juvenile male macaque monkeys (one Macaca fascicularis and one $M$. nemestrina) that weighed 3 and 6 $\mathrm{kg}$. Each animal sat in a primate chair during daily training and recording sessions, which lasted 2-6 hr. The animals were trained through operant conditioning to perform visual discrimination tasks and to switch freely between the tasks. A computer controlled the presentation of visual stimuli and monitored behavioral responses. During each task, the animal was required to maintain fixation on a small spot so that we could 

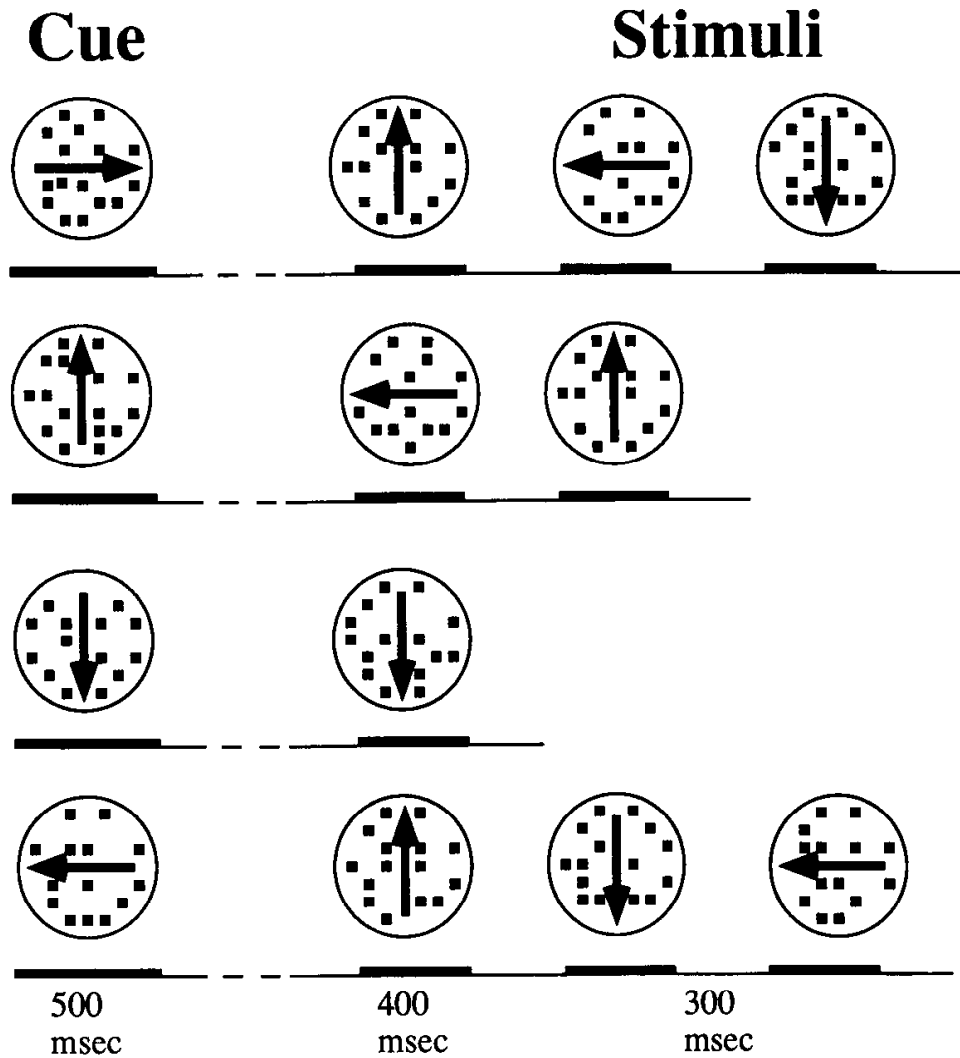

Figure 2. Representative trials from the direction matching task. Each trial began when the monkey pressed a small bar that triggered a $500 \mathrm{msec}$ presentation of the cue, that is, a pattern of dynamic random dots moving in one of four directions. This was followed by a variable delay of up to $540 \mathrm{msec}$. Then a sequence of stimuli were shown, each lasting $400 \mathrm{msec}$ and separated from the previous stimulus by $300 \mathrm{msec}$. The sequence always terminated in a pattern that matched the direction of the cue. The monkey was required to respond by letting go of the bar within $700 \mathrm{msec}$ of the onset of the match. The matching stimulus was turned off abruptly when the monkey made its response. control the retinal position of the visual stimulus. Partway through training, an aseptic surgery was performed to implant a headpost and scleral search coil (Judge et al., 1980), which enabled us to monitor eye position (Robinson, 1963; Remmel, 1984). The animals were required to maintain fixation within $1.0^{\circ}$ of the center of the fixation target while performing the task.

Visual stimuli were presented on a color video display $(55 \mathrm{~Hz}$ frame rate) located $76 \mathrm{~cm}$ in front of the animal. The stimuli used in this study consisted of dynamic random dots. A field of square white dots on a dark background was presented within a circular aperture. The rest of the display (except for the fixation mark) was a uniform gray of approximately the same mean luminance as the stimulus. The aperture remained fixed while the dots were moved coherently in one of four directions: up, down, left, or right. While the dots werc moving, they were also being individually replotted in random locations. This gave the stimulus a dynamic, twinkling appearance and prevented the occurrence of any spurious form cues that the animals might use to solve the task. Stimuli were presented at eccentric locations so that there was never any overlap between the fixation target and the stimulus aperture. Stimulus parameters such as aperture size and location, dot size and density, and speed were varied to optimize the response of the neuron in question. None of these variations had a noticeable effect on the animals' performance over the ranges used.

The physical characteristics of the random dot stimuli were as follows. Speeds ranged from 5.7 to 34.1 degrees/sec. Dot height and width ranged from $0.1^{\circ}$ to $0.4^{\circ}$, and density ranged from 0.5 to $3.7 \mathrm{dots} / \mathrm{degree}^{2}$. The diameter of the aperture through which the dots were visible varied between $3.2^{\circ}$ and $12.7^{\circ}$. The dynamic noise in the display can be characterized by determining the proportion of dots that, on average, moved coherently, which has been referred to as percentage correlation. For our stimuli, this correlation ranged from $95 \%$ to $99.8 \%$, far above monkeys' psychophysical threshold for direction discrimination (Newsome et al., 1989; Britten et al., 1992). Stimuli were positioned within the receptive fields of the neurons from which we recorded. The average stimulus eccentricities were $12.0^{\circ}(\mathrm{MT}), 14.3^{\circ}$ (MST), $15.2^{\circ}(7 \mathrm{a})$, and $5.9^{\circ}(\mathrm{V} 4)$.

The first task the animals learned was delayed match-to-sample using direction of motion as the matching criterion. This task is similar to that used in earlier studies of V4 neurons (Haenny et al., 1988; Maunsell et al., 1991) and is illustrated schematically in Figure 2. Each trial began with the appearance of the fixation target. The animal indicated that it was ready to begin the trial by fixating the target and depressing a lever that was mounted inside the front panel of the chair. After a $500 \mathrm{msec}$ delay, the cue (sample) appeared moving in a randomly selected direction. The cue remained on for $500 \mathrm{msec}$ and was followed, after a variable delay $(200-540 \mathrm{msec})$, by a sequence of test stimuli. The test sequence consisted of one to four stimuli moving in randomly selected directions, but always ended with a stimulus whose direction matched that of the cue. The test and cue stimuli always had the same size, speed, and retinal location. The test stimuli stayed on for $400 \mathrm{msec}$ and were separated by $300 \mathrm{msec}$. The animal was required to release the lever within $700 \mathrm{msec}$ after the onset of the matching stimulus in order to receive its reward. If the animal failed to respond within the $700 \mathrm{msec}$ window or if it released the lever too soon, the trial was aborted without reward. Trials were also aborted if the animal broke fixation at any time before it made its response.

Any of the four directions could be selected as the sample for any given trial. Test sequences were also selected at random with the constraint that no test direction appear more than once in a single sequence. Sample directions and test sequences were selected at random from a list that assured that every block of 16 correctly completed trials comprised a balanced presentation of the four directions: (1) each direction appeared equally often as the sample; (2) each direction appeared equally often in the first, second, third or fourth position of the test sequence.

The second task was formally the same as direction matching, except that color was used as the matching criterion. For color matching, the same random dynamic dots were used, but their speed was set to zero. Instead of four directions of motion, the dots were given one of four colors: red, green, blue, or yellow. No attempt was made to equate the luminances of the different colors. Although it is therefore possible that the animals might have used luminance to solve this task, we will refer to it as the color matching task. The animals learned to switch freely between direction matching and color matching. During data collection, the animals usually completed $80 \%$ or more of the trials correctly. Virtually all errors were due to breaks in fixation. Only data from correctly completed trials were used in the analysis. 


\section{Neuronal recording and data collection}

When behavioral training was complete, a recording chamber $(20 \mathrm{~mm}$ diameter) was implanted on the intact skull overlying the superior temporal sulcus (STS) or the prelunate gyrus. The recording chambers were positioned using stereotaxic coordinates derived from an atlas of the brain of $M$. fascicularis (Szabo and Cowan, 1984). Neuronal recordings were normally made daily during the 3 week sessions. At the start of each session, a $5 \mathrm{~mm}$ craniotomy was made inside the chamber, leaving the dura mater intact. Each day a hydraulic microdrive was mounted on the recording chamber, filled with sterile mineral oil, and sealed. Transdural recordings were made using $\mathrm{Pt} / \mathrm{Ir}$ or tungsten extracellular electrodes with impedances of about $1-2 \mathrm{M} \Omega$ at $1 \mathrm{kHz}$ (Wolbarsht et al., 1960). Signals from the microelectrode were amplified, filtered, and monitored on an oscilloscope and audio monitor.

The animal performed one of the matching tasks while we searched for units. Units were isolated on the basis of waveform, with the requirement that the peak of the action potential be at least three times the peak of the background noise. When a unit was isolated, stimulus parameters such as aperture size and location, dot size and density, and speed were adjusted to optimize its response. Data were then collected while the animal performed one of the tasks. When data collection ended for one set of conditions, we tested the unit with a different set of stimulus parameters or a different task. The order in which tasks were presented varied from unit to unit. Action potentials were converted to digital pulses with a window discriminator. The time of occurrence of action potentials was recorded with a precision of $1 \mathrm{msec}$. All other events (eye position, bar presses, stimulus onset and offset, etc.) were recorded with a precision of $5 \mathrm{msec}$. The time base used for action potential recording was synchronized with the vertical blank of the video display at the beginning of each trial.

A stimulus condition is defined by the identity of the current retinal stimulus (i.e., its direction or color) and the identity of the cue that is to be matched. This yields a total of 16 stimulus conditions for either task. Eight to ten repetitions of each stimulus condition were usually collected and averaged for data analysis. We excluded from the analysis those data files in which the unit was lost before completing at least four repetitions of each condition. Responses were computed as the average firing rate during a period starting $50 \mathrm{msec}$ after stimulus onset and ending $250 \mathrm{msec}$ later or when the animal made its response. For presentation of response histograms, spike density functions were produced by convolving peristimulus time histograms that had a $1 \mathrm{msec}$ binwidth with a discrete-time Gaussian pulse that had a standard deviation of $20 \mathrm{msec}$ and unit area.

\section{Quantitative analysis of neuronal responses}

The behavioral task we used required the animals to make a decision based on two pieces of information, the direction of the current retinal stimulus and the direction of the remembered cue. Our quantitative treatments of the data were aimed at determining how reliably the responses of single neurons encode each of these signals.

Selectivity index and ANOVA. For each stimulus presentation within a trial, we used the total number of action potentials fired by the neuron to compute an average firing rate. These firing rates were sorted into a four-by-four array of response distributions, indexed by stimulus direction and cue direction. This format allowed us to subject the response distributions to a two-way analysis of variance to determine if there was a significant modulation of the cell's response as a function of stimulus direction or cue direction. Responses to the cue itself were not included in this analysis.

We also computed cue and stimulus selectivity indices in the following manner. First, all the responses for a given stimulus direction were averaged together, combining responses from different cue directions. Likewise, responses were combined across different stimulus directions to determine the average response as a function of cue direction alone. From each set of averaged responses we calculated a selectivity index based on the responses to the preferred and least preferred stimulus or cue direction: selectivity index $=$ (preferred - least preferred $) /($ preferred + least preferred). Selectivity indices were computed without removing the spontaneous discharge rate from the response, so that we obtained index values in the range of $0-1.0$. An index of zero means that there was no difference between the preferred and least preferred response, while an index of 1.0 means that the neuron responded to the preferred stimulus but was silenced by the least preferred stimulus. A selectivity index of 0.33 corresponds to a preferred:null ratio of $2: 1$, while a selectivity index of 0.67 corresponds to a preferred:null ratio of $5: 1$.

$R O C$ analysis. The results of the ANOVA were confirmed using ROC analysis, a technique derived from Signal Detection Theory (Tolburst et al., 1983). We constructed ROC curves for each unit in order to determine how well the unit's responses could distinguish between its preferred and null stimulus or cue directions. For stimulus direction, we used responses from all presentations in which the preferred or null stimuli were present. For cue direction, we used all presentations following the preferred or null cue, regardless of which stimuli were present. The probability values that are derived from this analysis may be interpreted as the probability that an observer, who only has access to the cell's responses, will be able to identify correctly the stimulus (or cue) in a two-alternative forced-choice paradigm. It should be noted that the monkey's performance does not enter into the analysis at all, except for the fact that only neuronal responses from correctly completed trials were used.

\section{Histology}

During the last recording session, electrolytic lesions were made by passing a small current $(10 \mu \mathrm{A}$ for $20 \mathrm{sec})$ through the tip of the electrode. Each animal was then euthanized with barbiturates and perfused with phosphate-buffered saline followed by $4 \%$ paraformaldehyde fixative. Fiducial pins were inserted at known microdrive locations and the brain was removed, blocked, and allowed to equilibrate with $30 \%$ sucrose. Sections $40 \mu \mathrm{m}$ thick were cut on a freezing microtome. Alternate sections were stained for Nissl substance using cresyl violet or for myelin using a silver stain (Gallyas, 1979). The borders of area MT were located based on its distinctive myeloarchitectonics (Van Essen et al., 1981). The location of each cortical recording site was estimated based on microdrive readings and distance relative to lesions, pins and cortical borders.

Recordings were made from areas MT and MST in the superior temporal sulcus, 7a on the inferior parietal lobule, and V4 on the prelunate gyrus. Reconstructed recording sites for one animal are shown in Figure 3. Figure $3 A$ shows the STS opened up to reveal MT and MST recording sites. The borders of MT are indicated by the short-dashed lines. Figure $3 B$ shows the $\mathrm{V} 4$ and 7 a recording sites for the same animal. All V 4 and 7 a recordings were within $4 \mathrm{~mm}$ of the surface of the brain. The results for the second animal were essentially identical in all the relevant particulars.

\section{Eye position monitoring}

In order to determine whether signals are of extraretinal origin, it was necessary to replicate the same retinal stimulus under different behavioral conditions. Our ability to do so depended on training the monkeys to maintain fixation on a small spot for the $2-5 \mathrm{sec}$ duration of a trial. In separate control experiments we recorded and analyzed the monkeys' eye movements while they performed the matching task. The spatial resolution of the eye-monitoring system was approximately $0.05^{\circ}$. Horizontal and vertical eye position were recorded every $5 \mathrm{msec}$ while the monkeys performed 250-350 trials of the direction or color matching tasks. As during single-unit recording, the monkeys were required to keep their gaze within a $2^{\circ}$ window centered on the fixation target. However, the monkeys' overall precision was generally better than $0.5^{\circ}$, as indicated by the average rms error $\left(0.14^{\circ}\right.$ and $0.37^{\circ}$ for the two animals, respectively).

Although these fixation errors were relatively small, there was still sufficient latitude for systematic deviations of the eyes that might modulate the response to a particular cue or stimulus. We investigated this by sorting the eye-position samples for each stimulus presentation as a function of cue and stimulus direction (or color, depending on the task) to obtain mean eye position for each stimulus condition. The results for one animal performing the direction matching task are shown in Figure 4 (similar results were obtained for the other monkey). The mean eye positions (small rectangles) are shown with respect to the fixation window (large squares divided by dotted lines). The size of the rectangles indicates the rms fixation error. All of the eye-position rectangles are slightly offset due to a small misalignment between the center of the fixation window and the fixation target. However, the offset is almost exactly the same for all conditions. We looked for systematic deviations by performing a two-way ANOVA on the array of eye-position distributions. This analysis found no significant effect of stimulus direction $(p>0.1)$, but there was a significant effect of cue direction $(p<0.01)$; 
the means in the bottom row are displaced slightly to the upper left relative to the other rows. The magnitude of the shift, that is, the average difference between the bottom row and the row that was shifted the most in the opposite direction, is 4 arcmin. This corresponds to 2.5 pixels on the video monitor used to present stimuli. By means of comparison, microsaccades and slow drifts (measured in humans) have amplitudes averaging about 5 arcmin, but physiological tremor is much smaller, on the order of 20-30 arcsec (see Alpern, 1972). The fixation target was a white square 25 arcmin across. It is therefore unlikely that the monkey used a strategy of looking to one or another corner of the fixation target to encode cue direction. While it is conceivable that some neurons in visual cortex might be sensitive to the small systematic displacements we measured, we think it is unlikely that they could appreciably affect the responses to the dynamic moving stimuli in the areas that we examined.

\section{Results}

Stimulus- and task-related signals in parietal visual areas We collected data from 169 cells in the occipitoparietal pathway (66 MT, 57 MST, and 46 7a) while the animals performed the direction matching task. Figure 5 shows the response of a typical neuron in area MT. The action potentials fired by the neuron were summed over many trials of the behavioral task and collected into histograms. These histograms were sorted according to the direction of the retinal stimulus at the time of the response (horizontal axis) and the direction of the cue that was presented at the beginning of the trial (vertical axis). The line underneath cach histogram indicates the period when the stimulus was presented. Responses to the cue itself are not plotted. The four matching conditions are represented along the main diagonal; all other responses are to nonmatching conditions. The column of histograms on the right indicates the average responses to all stimuli following each of the different cues. The row of histograms on the bottom shows the response to each stimulus averaged over all cue directions. The response pattern shown is typical of MT neurons in that it has strong selectivity among different stimulus directions, in this case responding best whenever a upward-moving pattern of dots is presented. However, the response is largely independent of the cue direction that is being remembered.

Figure 6 shows a neuron recorded in area 7 a whose pattern of response is complementary to that shown for the MT cell in Figure 5. This cell has weak selectivity for stimulus direction, showing marginally stronger responses to downward- or leftward-moving dots than to the other two directions. This is best demonstrated in the row of histograms below the box, which show the response to each stimulus averaged over all cue conditions. This cell's responses are much more strongly modulated by the direction of the remembered cue, even though all responses shown here are to stimuli presented well after the cue has disappeared. On trials in which the animal was remembering an upward-moving cue (second row of histograms), the cell responded more strongly to all subsequent stimuli than when the animal was remembering a rightward-moving cue (third row of histograms). The column of histograms on the right shows the responses for each cue direction averaged over all four stimulus directions. The responses of this cell provide information regarding the direction of the remembered cue in much the same manner as the responses of the MT neuron in Figure 5 provide information regarding stimulus direction.

For each unit, we calculated a selectivity index (see Materials and Methods) based on the best and worst responses from the row and column averages demonstrated in Figures 5 and 6 . The "stimulus selectivity index" is simply the cell's conventional
A
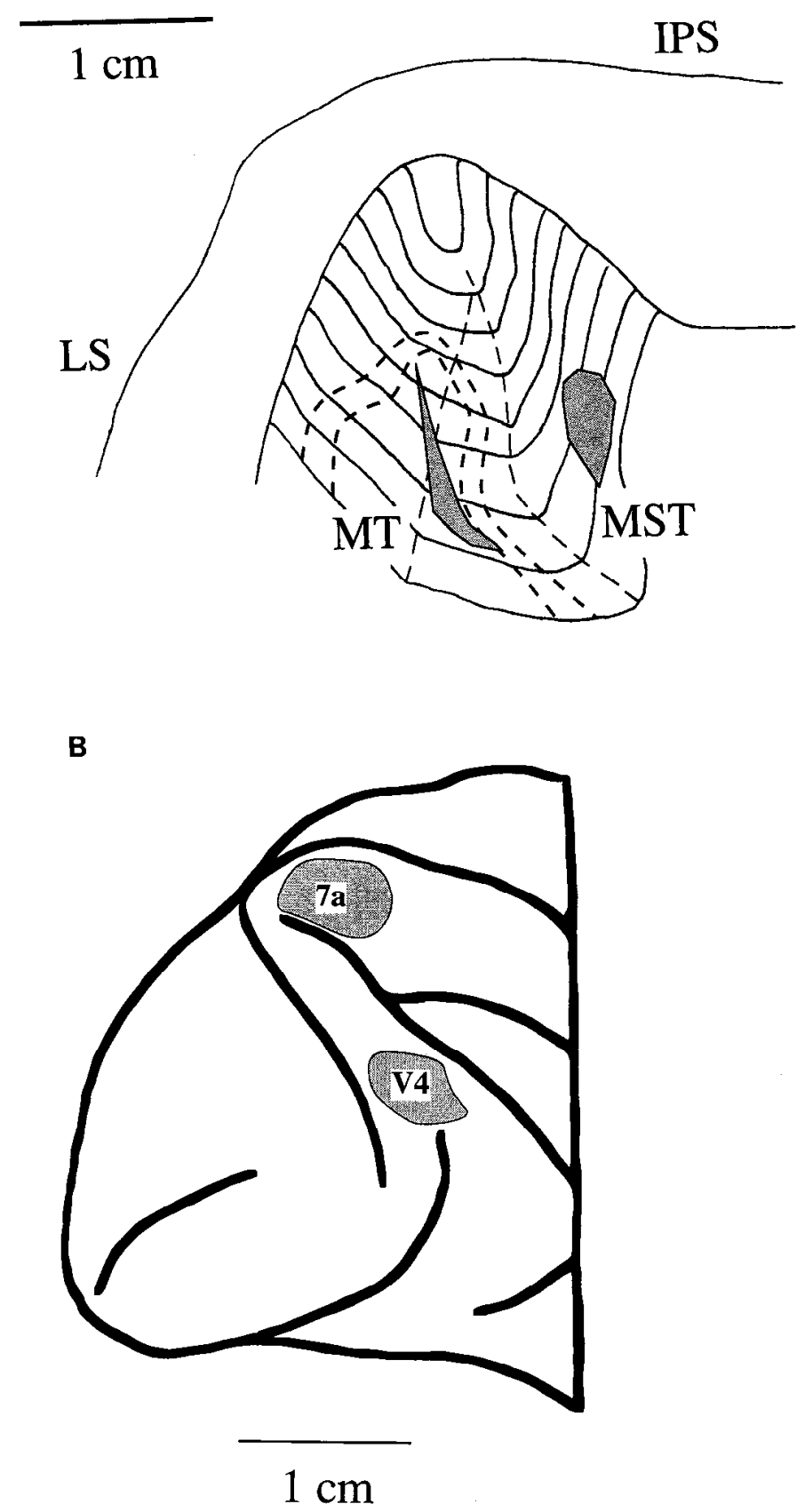

Figure 3. Recording sites from one monkey reconstructed from serial sections. $A$, The STS is opened up to reveal MT and MST recording sites $(d o t s)$. The short-dashed lines indicate the myeloarchitectonic borders of MT (the separation between the two lines indicates our level of confidence in assigning this border). The large-dashed lines indicate where the sulcus started to curve anteriorly, with the rightmost line being the anterior tip of the sulcus. $L S$, lunate sulcus; IPS, intraparietal sulcus. B, Lateral view of the posterior third of the monkey's brain showing V4 and 7 a recording sites.

direction selectivity, while the "cue selectivity index" is a measure of the strength of the extraretinal signal carrying information about the identity of the cue. The distributions of cue and stimulus selectivity indices for all parietal units are shown in Figure 7. The results for MT show a striking disparity between retinal and extraretinal signals. Almost all of the MT neurons have stimulus selectivity indices greater than $0.33(2: 1$ preferred: 


\section{Stimulus}

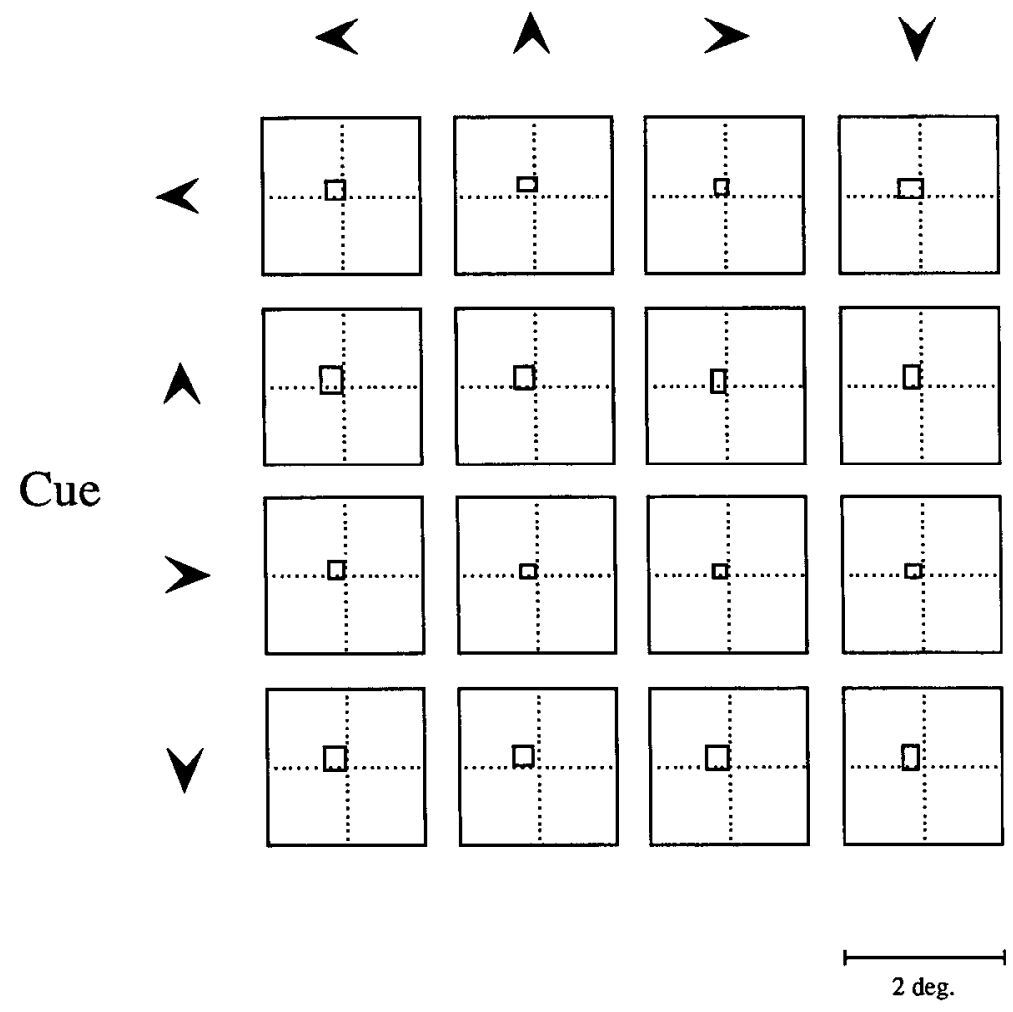

null ratio), while none of them has a cue index that high. At progressively higher levels of the parietal pathway, MST and $7 \mathrm{a}$, stimulus selectivity appears to become weaker while extraretinal signals become stronger. Part of the weaker direction selectivity in MST and 7a may be due to the fact that the stimulus we used might not be optimal for cells that prefer rotating or expanding/contracting patterns of motion (Saito et al., 1986)

The four-by-four array of responses for each neuron was subjected to a two-way ANOVA to determine the statistical significance of the stimulus and cue selectivities. Figure $8 A$ shows the percentage of units for each area whose responses were modulated by stimulus or cue direction at the $p<0.05$ significance level. It should be noted that the properties of stimulus selectivity and cue selectivity do not necessarily go together. A cell need not have conventional direction selectivity in order to show an effect of cue direction. The percentage of cells that possess both types of selectivity is shown in Figure $8 A$ (columns labeled "stim \& cue"), alongside of which are the predicted percentages assuming that the two types of selectivity are distributed independently across the sample of neurons in each area. There is nearly exact agreement between the observed conjunction of stimulus and cue selectivities and the random prediction. Another way to demonstrate the independence of stimulus and cue direction signals is to look at the correlation between the selectivity indices for single units. In MT and MST there was no significant correlation between the stimulus and cue selectivity indices (MT: $r=-0.19, p=0.08$; MST: $r=0.07, p=0.56$ ). In area $7 \mathrm{a}$ there was only a weak correlation $(r=0.25, p=$ 0.04).

We used the results of the ANOVA to select units that showed either a significant cue or stimulus effect. Figure $8 A$ shows the mean $( \pm$ SEM) stimulus and cue selectivity indices for these cells. These means are not greatly different from those derived from the distributions of all units (Fig. 7). Figure 9 shows the average response as a function of stimulus and cue direction for cells with significant response modulation. The responses of each cell were shifted so that the preferred direction for all cells superimposed at $0^{\circ}$. These response curves were constructed without normalizing the individual cell responses in order to show the average change in firing rate going from the null to preferred direction. The error bars indicate the variability ( \pm SEM) among neurons.

A further test of the reliability of cue and stimulus direction signals was obtained through ROC analysis. As expected, almost all MT neurons (97\%) discriminated between their preferred and null stimulus directions better than $75 \%$ of the time. The percentage of units that discriminated stimulus direction at the $75 \%$ correct level fell to $58 \%$ in MST and to only $13 \%$ in $7 \mathrm{a}$. For signaling the direction of the remembered cue, most MT cells perform at less than $60 \%$ correct. A few MT cells performed somewhat better than chance and may have carried useful signals. The reliability of the cue direction signal shifted toward higher probabilities at later stages of the parietal pathway (mean ROC $p$ values: MT, $0.54 \pm 0.01$; MST, $0.57 \pm 0.01 ; 7 \mathrm{a}, 0.57$ \pm 0.01 ). Only MST and $7 \mathrm{a}$ had any cells whose performance was better than $75 \%$ correct. In all of the parietal pathway, only three cells (two in MST, one in 7a) were found to exceed the $75 \%$ correct performance level for signaling cue direction.

\section{Stimulus- and task-related signals in visual area V4}

We recorded from 94 cells in V4 while animals performed the direction matching task. Even though V4 has been reported to 


\section{Stimulus}

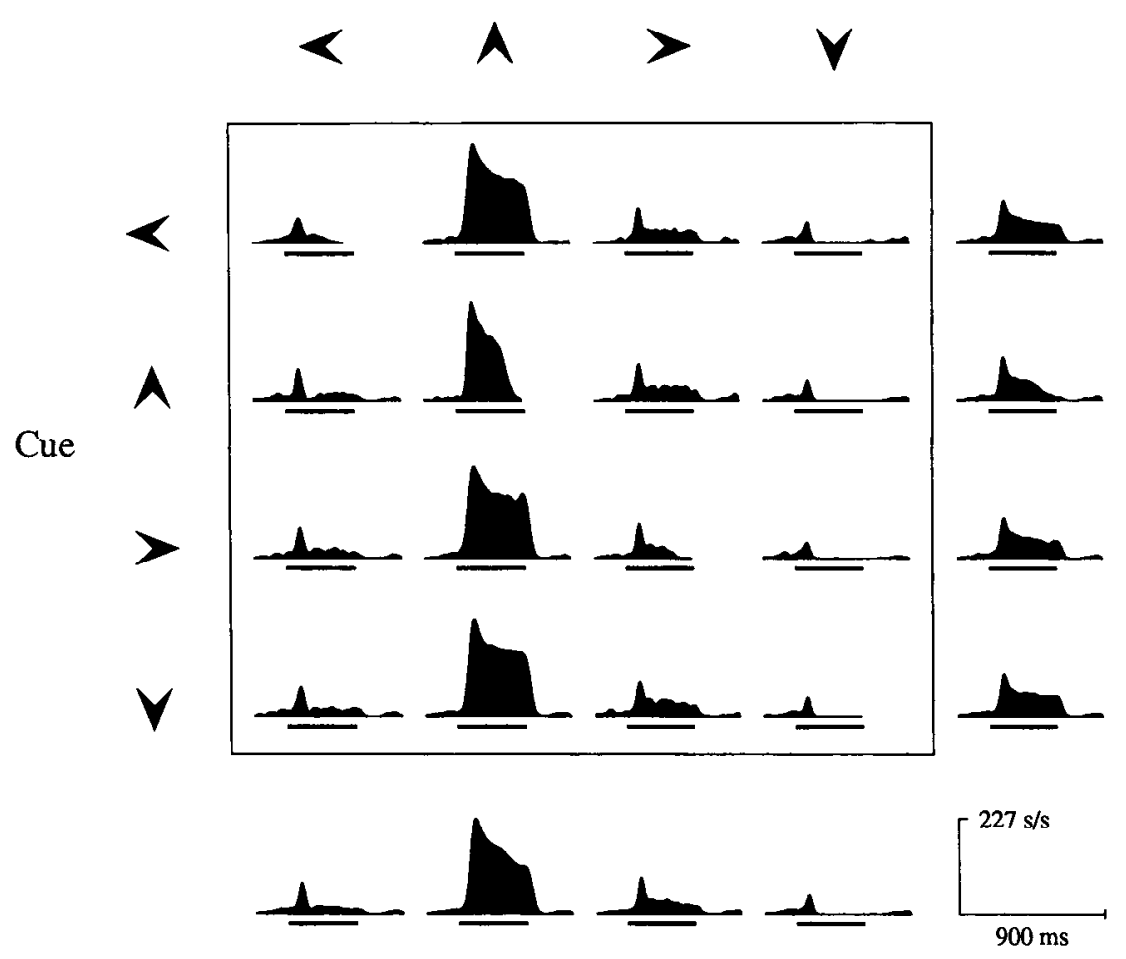

Figure 5. Activity of a single MT neuron collected during the direction matching task. The box encloses a four-by-four array of response histograms that represent the 16 different combination of cue and test stimulus directions that occurred during the matching task. Each column represents responses to a particular test stimulus, sorted into rows according to the direction that the animal was seeking to match at the time the stimulus appeared. Responses to the presentation of the cue itself are not shown. Each plot is the average of 16 stimulus presentations, and the bars below each show the period during which the stimulus was on. The response histograms were smoothed by convolving with a unit Gaussian. Responses to matching conditions (main diagonal) were truncated at the time the monkey made its response, which varied from trial to trial. Therefore, plots on the principal diagonal are responses to matching conditions, and are truncated at the time the animal made its behavioral response. As the monkey's reaction time varied from trial to trial, the average neuronal response appears to taper off when in fact each individual response ended abruptly (with some latency) at the time the monkey responded and the stimulus was turned off. Plots below and to the right of the box show the column and row averages. The responses of this cell were typical of those in MT in showing a strong response to a particular stimulus direction with very little modulation by the cue.

contain few direction-selective neurons, previous research (Maunsell et al., 1991) has suggested that extraretinal signals for this type of task might not be tightly coupled to the sensory processing capabilities of a particular area. Furthermore, in the small percentage of parietal neurons that show strong reliable extraretinal signals with direction matching, there is little correlation with conventional direction selectivity. It is therefore not unreasonable to suppose that V4 neurons might carry an extraretinal signal for remembered direction, despite their weaker conventional direction selectivity. The relatively weak effects found in parietal cortex provided further incentive to look elsewhere for stronger cue direction signals.

The array of histograms in Figure 10 shows the responses of a V4 neuron to stimulus presentations taken from trials of the direction matching task. The responses are sorted as a function of the direction of the retinal stimulus (columns) and the direction of the cue that was presented at the beginning of the trial (rows). The cell has a strong visual response to most stimulus presentations, but little conventional direction selectivity; it shows a slight preference for upward-moving stimuli over the other three directions. However, the response of the cell is strongly modulated depending on the direction of the remembered cue. In this case, responses to stimuli that followed an upward-mov- ing cue were much stronger than responses to stimuli following a rightward cue.

The distributions of cue and stimulus selectivity indices for all V4 neurons tested are shown in Figure $11 \mathrm{~A}$. Conventional direction selectivity was about the same as that found in other studies (Desimone and Schein, 1987; Mountcastle et al., 1987), with about $33 \%$ of the cells showing at least a $2: 1$ difference in their preferred and null responses. The same degree of direction selectivity for the remembered cue was seen in $24 \%$ of V4 neurons.

Many V4 neurons ( $n=50$ ) were also tested while the animals performed a color matching task. As our aim was not to characterize the chromatic properties of V4 neurons, we did not equate the colored stimuli for luminance. While, technically, the cells' stimulus selectivities in this task confound luminance and color, we think it likely that the animals' behavior and the related extrarctinal signals wcre detcrmined by the more salient stimulus dimension (color). In any case, this task allowed us to compare extraretinal signals for direction matching with those elicited in a nonmotion task. The distributions of selectivity indices for this task are shown in Figure $11 B$. The colored stimuli resulted in higher selectivity indices for V4 neurons relative to moving stimuli, with $33 \%$ of the cells showing at least $2: 1$ 
Stimulus

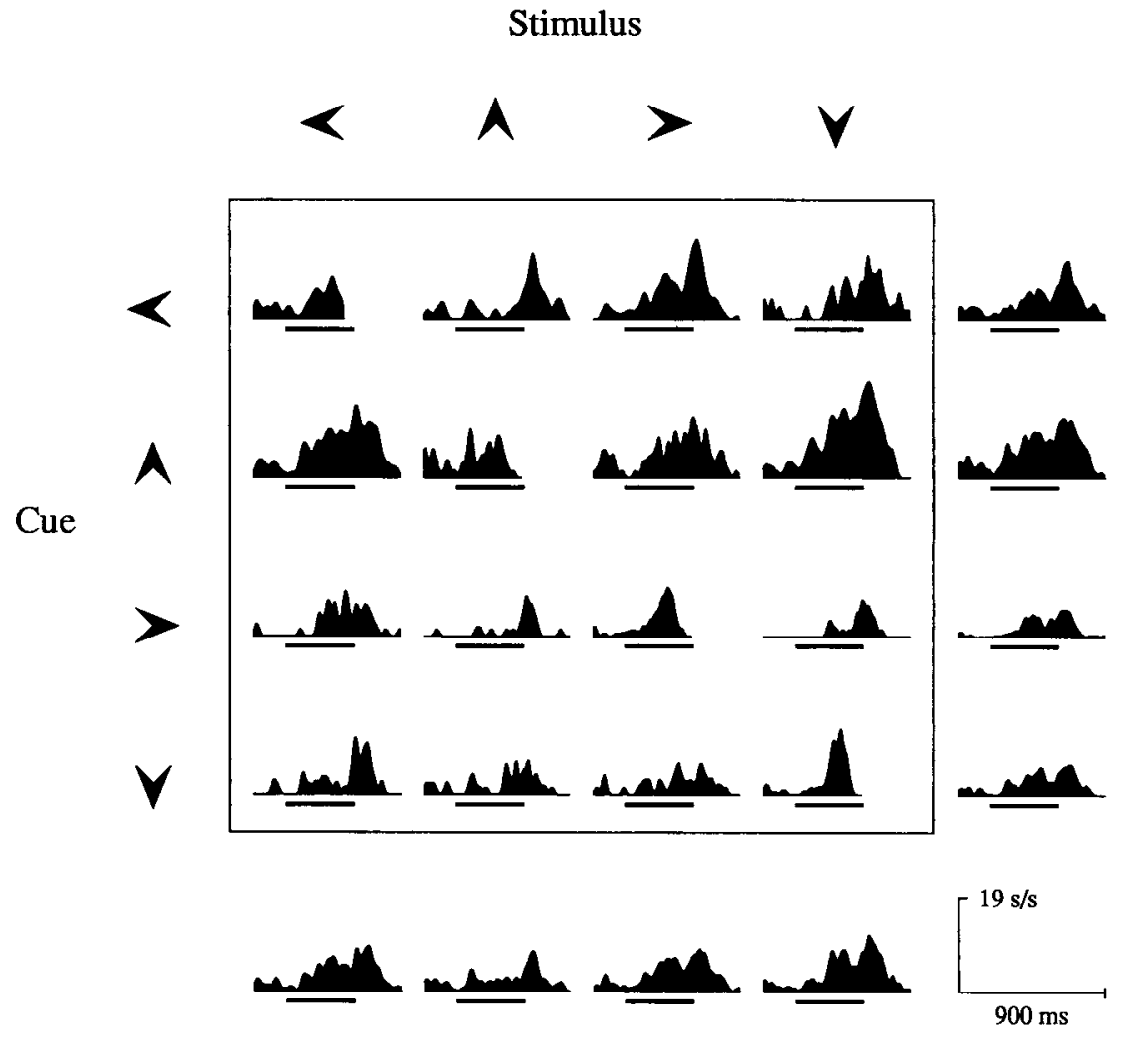

Figure 6. Activity of a single arca 7a matching. The description is the same as that for Figure 5. The responses of this neuron showed very little selectivity for stimulus direction, but appeared to be strongly modulated by the direction of the cue, even though it was no longer present at the time the response occurred. neuron collected during direction

response modulation. This indicates that the colored stimuli were more discriminable to V4 neurons than were plain white moving dots. However, the color matching task produced weaker extraretinal signals than the direction task. Only $7.8 \%$ of V4 neurons had cue selectivity indices greater than $2: 1$ for color matching.

We used a two-way ANOVA to analyze the significance of signals for direction and color matching in V4. Figure $12 \mathrm{~A}$ gives the percentage of neurons that had significant stimulus or cue effects for the two tasks (at the $p<0.05$ level). The bars labeled "stim \& cuc" show thc percentagc of ncurons that had both a significant stimulus effect and a significant cue effect. These percentages are similar to what one would expect if the properties of stimulus and cue selectivity were independently distributed across the population ("prediction"). Figure $12 B$ shows the mean selectivity indices $( \pm$ SEM) for units that reached significance for stimulus or cue effects. Overall, a higher percentage of cells had significant cue effects for direction matching than for color matching. However, for cells that showed a significant effect, the average cue selectivity index was about the same for both tasks.

Response "tuning curves" were constructed by averaging all units that had significant stimulus or cue effects, and are shown in Figure 13. Each set of responses was shifted so that the preferred responses of all cells superimposed at $0^{\circ}$ For color matching, the stimuli were arranged in their natural spectral order (red, yellow, green, blue) and then mapped onto polar coordinates starting with red, and proceeding in a clockwise direction through yellow, green, and blue (Derrington et al., 1984). This allowed us to treat the four colors in a manner analogous to the four directions of motion.

ROC probability values were computed for direction and color matching in V4. The average performance of V4 neurons was
$62 \%$ correct for discriminating stimulus direction and $60 \%$ correct for discriminating cue direction. However, a substantial number of cells had better than $75 \%$ correct performance: 8 of 94 for stimulus direction and 9 of 94 for cue direction. The average ROC probability for discriminating cue direction was significantly greater in V4 than for MT, MST or 7a (unpaired $t$ test, one tailed, $p<0.05$ ). For color matching, the average performance was $66 \%$ correct for stimulus color and $58 \%$ correct for cue color. Again, a substantial number of cells were over the $75 \%$ correct mark for stimulus color (13 of 50 ), but only onc unit was as reliable at signaling the color of the remembered cue.

Testing cells with two different tasks provided a partial control for the effects of systematic eye movements. For any given cell, the stimuli used in the two tasks were identical in spatial extent, position, dot size, and density, and differed only with regard to the presence or absence of motion or color. If systematic eye movements were the cause of artifactual cue effects in cells that were particularly sensitive to the spatial position of the stimulus, one would expect to see this effect regardless of which task the animal was performing. Of the 44 cells that were tested on both tasks, 19 had a significant cue effect for direction. Only 10 of these also had a significant cue effect for color. For cells that had significant cue effects on both tasks, there was a very weak correlation between the cue selectivity indices $(r=0.57, p=$ $0.09, n=10$ ). While there is still the possibility that the animals' eye-movement behavior differed between the two tasks, thesc results reduce the likelihood that cells simply responded to small differences in retinal stimulus position that might be correlated with the identity of the cue.

There was generally good agreement between the ROC probabilities and the two other measures used to quantify cell responses: the selectivity indices and the ANOVA $p$ values. Table 

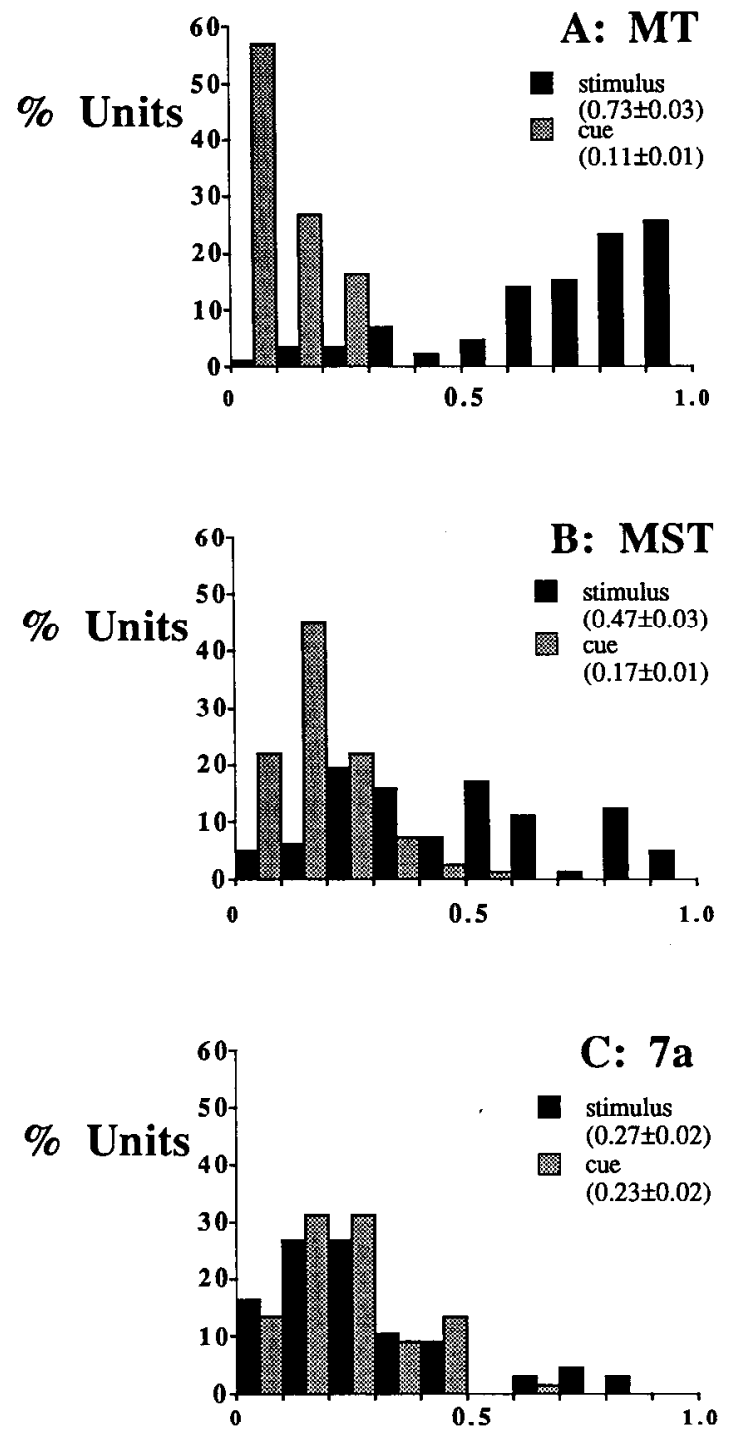

\section{Selectivity Index}

Figure 7. Distributions of cue (gray bars) and stimulus (black bars) selectivity indices by area for all parietal neurons. Selectivity indices range from 0 (no difference between preferred and null response) to 1.0 (no response to the null direction). Each bin contains the percentage of total units that had indices equal to or greater than the value of the left tick mark and strictly less than the value of the right tick mark. For example, close to $60 \%$ of MT neurons had cue direction selectivity indices that were less than 0.1 and none had a cue SI greater than or equal to 0.3 . The numbers in parentheses are the mean ( \pm SEM) stimulus and cue selectivity indices.

1 gives the corrclation cocfficients and their attendant probabilities (in parentheses) for the linear regression of ROC probability against selectivity index and against ANOVA probability. The selectivity index is based on mean responses and takes no account of the variance of the response distributions, as does the ROC analysis. Thus, the agreement between ROC and selectivity index is best when the selectivity index as well as the maximum firing rate are high, as in MT. It is here that there is the greatest absolute difference between the preferred and null responses, and response variance plays a minor role. The agreement between ROC and ANOVA is generally stronger, as both take variance into account. However, the ROC, which makes
$\mathbf{A}$

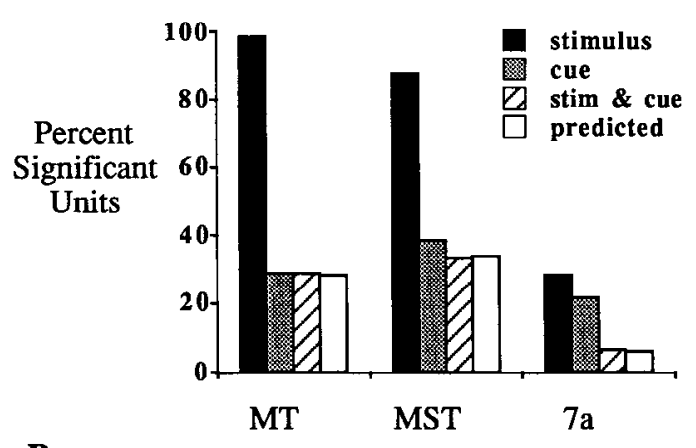

$\mathbf{B}$

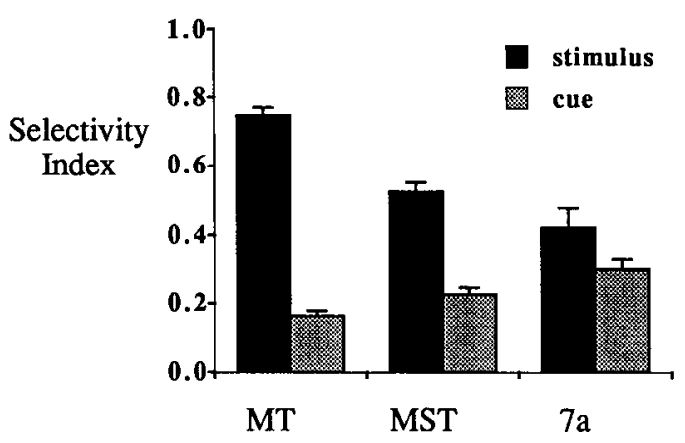

Figure 8. Results for all parietal neurons of a two-way ANOVA used to test the reliability of cue and stimulus direction signals. $A$. Percentage of neurons by area that reached significance at the $p \leq 0.05$ level for stimulus direction (black bars) and cue direction (graybars). The hatched bars indicate the percentage of units that reached significance for both stimulus and cue direction along with the proportion of such neurons that would be expected if the properties of stimulus and cue direction selectivity were distributed independently among the population of neurons. $B$, Average cue and stimulus direction selectivity indices (mean \pm SEM) for units that had significant $p$ values.

no assumptions about the shape of the response distributions, is probably the more accurate measure of signal reliability.

\section{Delay period activity}

Previous studies (Fuster and Jervey, 1981; Miyashita and Chang, 1988; Fuster, 1990; Miller et al., 1993) have found that some IT neurons carry task-specific signals during the delay period following the presentation of the cue in a delayed match-tosample task, thus raising the issue of whether similar signals might be found in other areas. The studies done in IT used delays of several seconds in duration, whereas in the present study we used a delay that varied randomly between 200 and $540 \mathrm{msec}$. This short duration raises the possibility that delay activity will be dominated by a purely sensory response to the offsct of the cue. To minimize this risk, we counted only spikes that occurred at least $350 \mathrm{msec}$ after the disappearance of the cue. Furthermore, we only analyzed activity during the interval between the cue and the first test stimulus, as the subsequent interstimulus intervals were only $300 \mathrm{msec}$ in duration (see Fig. 2). Our analysis was aimed at discovering (1) whether there was any significant difference between delay activity and spontaneous discharge, and (2) whether the delay activity was modulated in a way that could carry information about the cue.

Spontaneous background activity was measured over an interval of $400 \mathrm{msec}$ preceding the onset of the cue while the monkeys fixated a small white square on an otherwise blank 


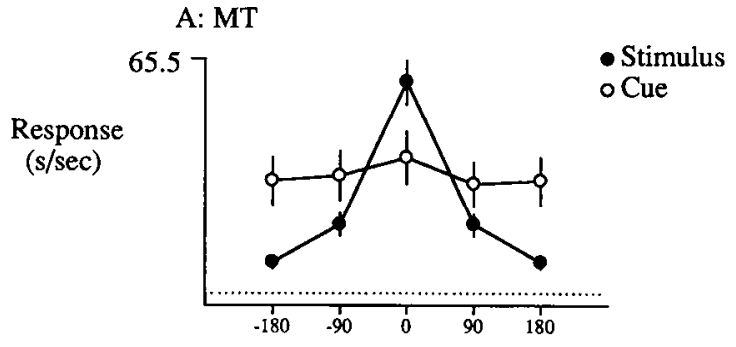

B: MST

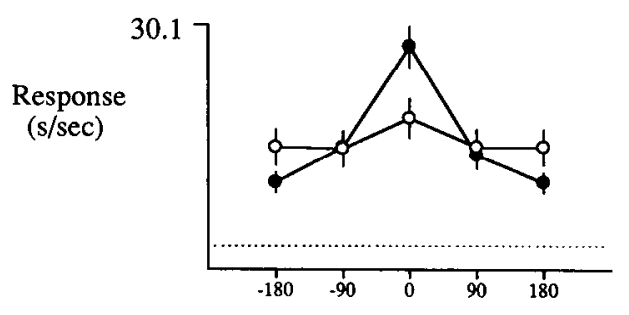

C: $7 \mathbf{a}$

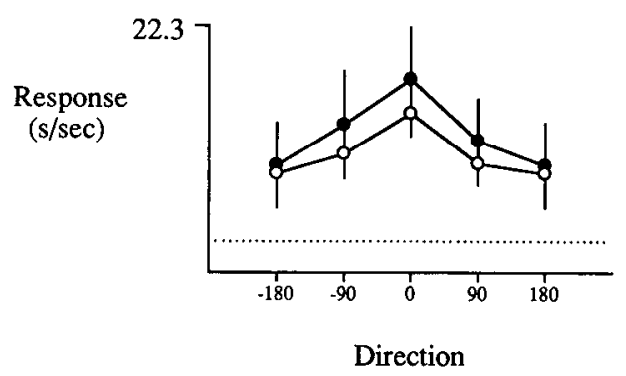

Figure 9. Direction "tuning curves" constructed by averaging the raw responses of all units found to have statistically significant stimulus or cue direction selectivity. For each unit and condition (i.e., stimulus or cue direction) the responses were shifted so that the preferred responses are aligned. The horizontal axis indicates direction of motion relative to the preferred direction. The vertical axis is the average response in terms of spikes/sec. The error bars represent \pm 1 SEM. The dotted lines are the average spontaneous activity.

(mean luminance) screen. Spontaneous rates were generally low (average spikes/sec: MT, 3.7; MST, 3.0; 7a, 2.9; V4, 1.7). For each cell, we pooled the entire set of delay activities and compared that to the spontaneous rate. An unexpectedly high percentage of neurons in all four visual areas had delay activity that was significantly greater than the background (unpaired $t$ test, two tailed, $p \leq 0.05 ; 32 \% \mathrm{MT}, 60 \% \mathrm{MST}, 56 \% 7 \mathrm{a}, 21 \%$ V4). For all cells, the average delay activity was about twice as great as the background (average spikes/sec: MT, 7.3; MST, 7.9; 7a, 6.1; V4, 3.3). The average delay activity in V4 was significantly lower than that in MT, MST and 7a, but there were no significant differences among the three parietal areas (unpaired $t$ tests, two tailed, $p>0.1$ ). The percentages of cells for which delay activity was significantly below background at the $p \leq$ 0.05 level was close to the expected $5 \%$ for MST and 7 a $(7 \%$ and $4 \%$, respectively), but greater than expected for MT and V4 (20\% and $23 \%$, respectively).

There was a consistent but weak correlation between direction selectivity and delay period activity. Cells with high delay activity generally had low direction indices. The direction indices for cells with low delay activity were evenly distributed. The same relationship held for both stimulus and cue direction indices. Correlation coefficients were in the range of $0.2-0.4$ and were significant at the $p \leq 0.05$ level. The only exception was the correlation between cue direction index and delay activity in MT, which was not significant ( $r=0.003, p=0.98)$.

One hypothesis regarding delay activity is that it represents the actual short-term memory of the cue. However, we saw no evidence that delay activity in V4 was related to the identity of the cue. We sorted delay activities by cue direction and performed a one-way ANOVA for each cell. The percentages of cells that showed significant modulation at the $\mathrm{p} \leq 0.05$ level were near or below the expected $5 \%$ for all four areas (MT, $4.5 \%$; MST, $3.5 \% ; 7 \mathrm{a}, 6.7 \% ; \mathrm{V4}, 3.2 \%)$. None of the two or three cells per cortical area that were significantly modulated had very striking effects. Thus, while these results suggest that most cells experienced some change in excitability as measured by significantly increased or decreased overall levels of activity during the delay, there was no evidence that this activity carried information about the identity of the cue for any significant number of cells.

\section{Responses to matching and nonmatching stimuli}

Miller et al. (1993) found that many AIT neurons responded differentially to match and nonmatch conditions in a delayed match-to-sample task similar in design to the one used in this study. These authors found that about $44 \%$ of their sample of IT cells responded better to nonmatching stimuli, while only $4 \%$ responded better to matching stimuli. We applied a similar analysis to our data, except that where Miller and co-workers compared the match/nonmatch responses to all stimuli (using a two-way ANOVA), we only compared the responses to each cell's preferred stimulus. Furthermore, we counted only those spikes that occurred between 50 and $200 \mathrm{msec}$ after stimulus onset so that the truncation of the matching stimulus due to the

\begin{tabular}{|c|c|c|c|c|c|}
\hline & MT & MST & $7 a$ & V4 direction & V4 color \\
\hline \multicolumn{6}{|c|}{ ROC vs selectivity index } \\
\hline Stimulus & $\begin{array}{l}0.77 \\
(p<0.0001)\end{array}$ & $\begin{array}{l}0.84 \\
(p<0.0001)\end{array}$ & $\begin{array}{l}0.47 \\
(p<0.0001)\end{array}$ & $\begin{array}{l}0.53 \\
(p<0.0001)\end{array}$ & $\begin{array}{l}0.56 \\
(p<0.0001)\end{array}$ \\
\hline Cue & $\begin{array}{l}0.58 \\
(p<0.0001)\end{array}$ & $\begin{array}{l}0.55 \\
(p<0.0001)\end{array}$ & $\begin{array}{l}0.32 \\
(p<0.008)\end{array}$ & $\begin{array}{l}0.50 \\
(p<0.0001)\end{array}$ & $\begin{array}{l}0.46 \\
(p<0.0006)\end{array}$ \\
\hline \multicolumn{6}{|c|}{ ROC vs ANOVA } \\
\hline Stimulus & $\begin{array}{l}-0.52 \\
\quad(p<0.0001)\end{array}$ & $\begin{array}{l}-0.60 \\
\quad(p<0.0001)\end{array}$ & $\begin{array}{l}-0.69 \\
\quad(p<0.0001)\end{array}$ & $\begin{array}{l}-0.65 \\
\quad(p<0.0001)\end{array}$ & $\begin{array}{l}-0.60 \\
\quad(p<0.0001)\end{array}$ \\
\hline Cue & $\begin{array}{l}-0.54 \\
\quad(p<0.0001)\end{array}$ & $\begin{array}{l}-0.49 \\
\quad(p<0.0001)\end{array}$ & $\begin{array}{l}-0.65 \\
\quad(p<0.0001)\end{array}$ & $\begin{array}{l}-0.64 \\
\quad(p<0.0001)\end{array}$ & $\begin{array}{l}-0.76 \\
\quad(p<0.0001)\end{array}$ \\
\hline
\end{tabular}




\section{Stimulus}

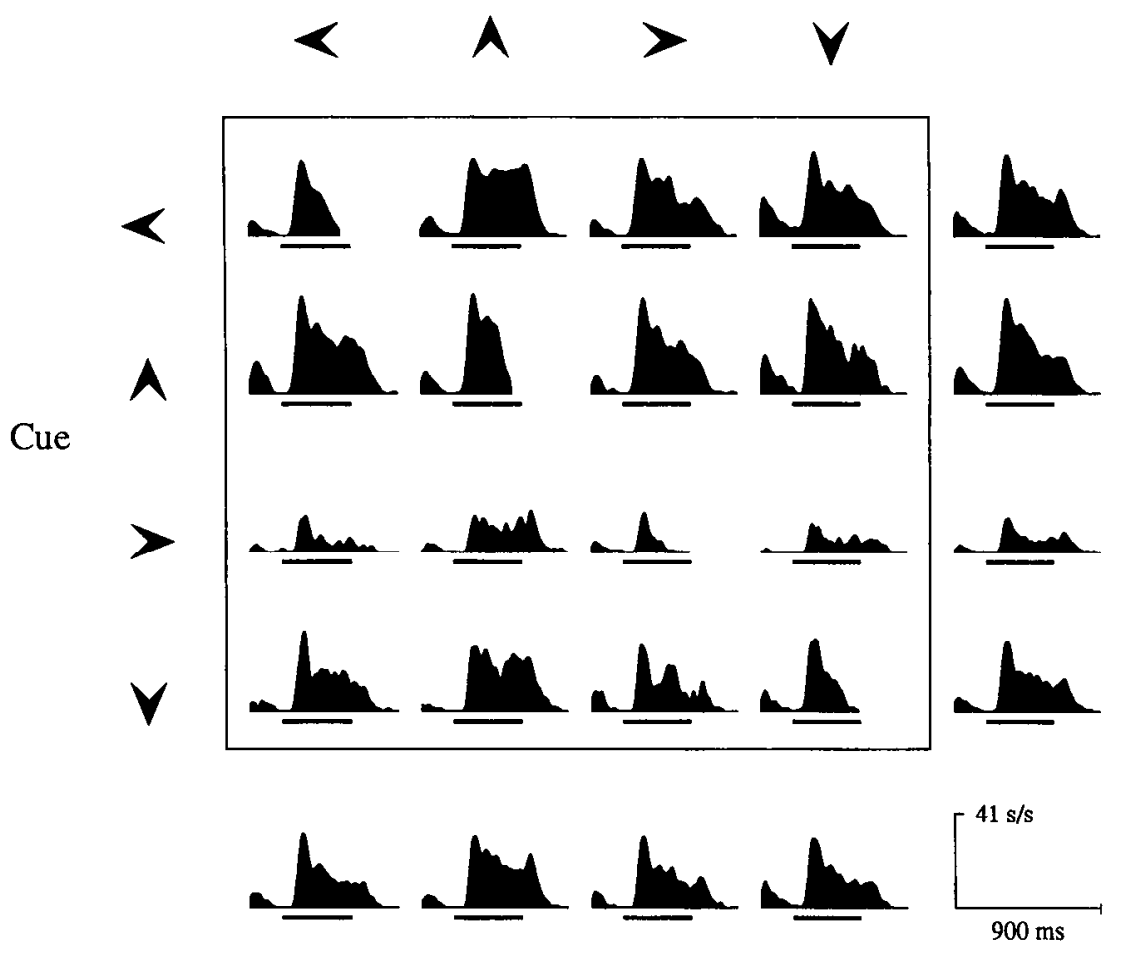

Figure 10. Activity of a single area V4 neuron collected during direction matching. The description is the same as for Figure 5. The responses of this neuron showed very little selectivity for stimulus direction, but appeared to be strongly modulated by the direction of the cue, even though it was no longer present at the time the response occurred.

animal's behavioral response (which usually occurred at around $300 \mathrm{msec}$ ) would not affect the results. We found that about $30 \%$ of the cells in MT and V4, and smaller proportions in MST and $7 \mathrm{a}$, responded significantly more strongly to nonmatching stimuli (unpaired $t$ test, two tailed, $p \leq 0.05$; MT, 27\%; MST, $18 \% ; 7 \mathrm{a}, 9 \% ; \mathrm{V} 4,28 \%$ ). Very few cells had significantly stronger responses to matching stimuli (MT, $8 \%$; MST, 2\%; 7a, 2\%; V4, $1 \%$ ).

We quantified the relative magnitude of this effect by calculating a suppression index: suppression index $=$ (nonmatch match $) /($ nonmatch + match). This calculation results in an index that varies between -1.0 (no response to the nonmatch) and 1.0 (no response to the match). When averaged over all cells, suppression indices in MT and MST were quite small; however, more appreciable effects were found in $7 \mathrm{a}$ and V4 (average SI $\pm \mathrm{SE}: \mathrm{MT}, 0.02 \pm 0.01 ; \mathrm{MST}, 0.05 \pm 0.01 ; 7 \mathrm{a}$, $0.14 \pm 0.03 ; \mathrm{V} 4,0.13 \pm 0.02$ ). The absolute differences in firing rate, again averaged over all units, were on the order of 1-3 spikes/sec for all areas (MT, $2.7 \pm 0.8 ; \mathrm{MST}, 1.6 \pm 0.5 ; 7 \mathrm{a}, 1.2$ $\pm 0.3 ; \mathrm{V} 4,1.4 \pm 0.3$ ). The overall impression is that there is some small but significant response suppression to the match in a minority of cells in all four visual areas. If one considers jointly the percentage of suppressed cells and the average suppression index, the effect is somewhat stronger for V4 than for the parietal areas. There was no evidence for significantly enhanced responses to matching stimuli.

\section{Discussion}

Object identification in primates depends on the temporal visual pathway (see Dean, 1976). Motion processing, on the other hand, is thought to be primarily a function of the parietal pathway. But motion may be considered both as a cue for visually guided movement/spatial orientation and/or as a feature to be identified, depending on the task requirements. When motion is used in a task that calls for feature identification, which pathway signals the behavioral context? Would such a task reveal signals of cognitive value in the parietal pathway, or would these signals be found in the temporal pathway, despite its presumed inferiority in motion processing? We tested these possibilities using match-to-sample, a task that has been used previously to demonstrate task-specific processing in the temporal pathway (Fuster and Jervey, 1981; Haenny et al., 1988; Miyashita and Chang, 1988; Maunsell et al., 1991). However, the stimuli we used were moving dynamic random dot patterns in which the only information relevant to the task was direction of motion.

In the direction matching task, the animal views a sequence of moving stimuli and is required to remember the direction of the first stimulus (the "cue") and compare that with the direction of each subsequent stimulus as it is presented. We found that extraretinal signals related to the remembered direction of motion are more reliable and are found earlier in the temporal visual pathway than in the parietal pathway. Many neurons in area $\mathrm{V4}$, part of the temporal pathway, showed response modulation that was specific to the direction of the remembered cue. Area MT is at a level comparable to V4 in the cortical hierarchy, but is part of the parietal pathway. Responses in MT, though highly selective for the direction of the immediate retinal stimulus, carried rather weak signals for the direction that the animal was remembering. At later stages of the parietal pathway, areas MST and 7a, more cells appeared to show selectivity for the remembered direction. Furthermore, the statistical reliability of cue direction signals was somewhat greater in MST and 7a than in MT. Cells in area V4 carried the most reliable signals for remembered direction with $10 \%$ of cells in V 4 showing an ability to discriminate between different remembered directions at the $75 \%$ correct level. This compares to zero MT neurons, and only 

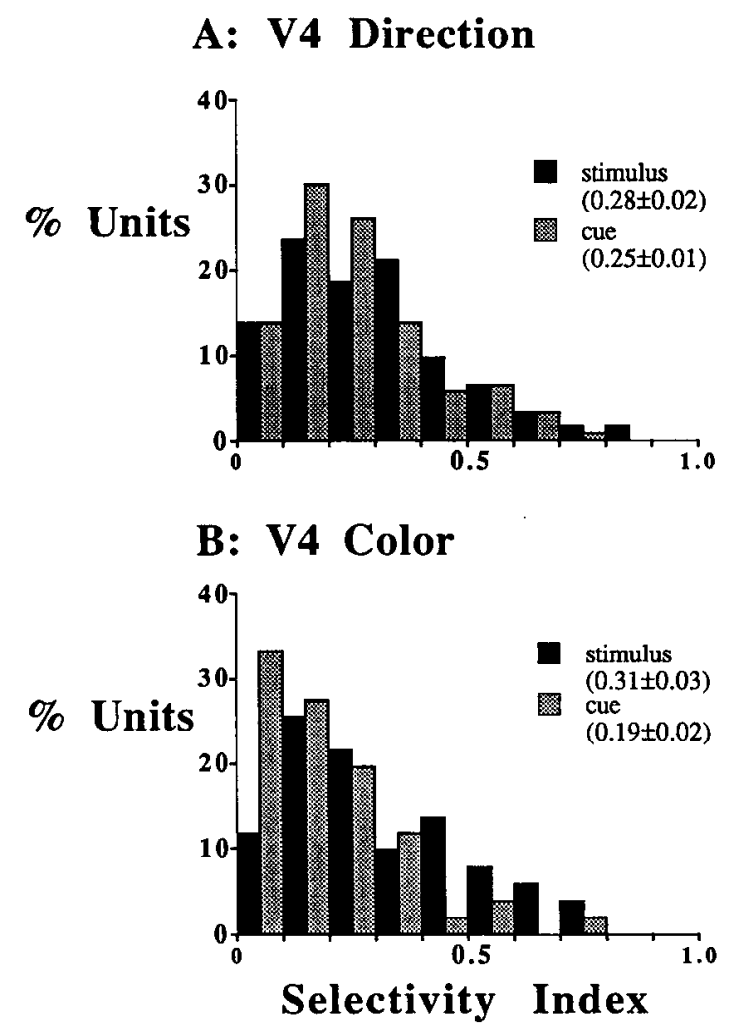

Figure 11. Distributions of cue and stimulus selectivity indices for area V4 (see Fig. 8 legend). $A$, Distributions for 94 neurons tested with direction matching. $B$, Distributions of 50 neurons tested with color matching. Almost all of the color matching neurons came from the population that were tested for direction.

$3 \%$ of neurons in MST and 7a combined. These results suggest that extraretinal signals for direction matching are more reliable in the temporal pathway, although this interpretation should be tempered by the fact that the stimuli were not optimal for all areas and that we only recorded from one node of the temporal pathway.

Previous work has tended to characterize the visual system as a network of discrete and highly specialized modules (Zeki, 1978). These modules are thought to break down the visual image into its constituent elements-motion, color, depth, orientation, and so on-such that each module uses one specific kind of information to construct its own feature map of the visual scene. In this scheme, the role of cognitive variables, such as attention, is to enhance processing of a particular stimulus dimension or region of visual space, that is, to select a particular feature map or location within a feature map (see Triesman, 1988). This view has received support in recent studies by Corbetta et al. $(1990,1991)$, in which they looked at the activation of different cortical areas using PET while human subjects performed a task requiring selective attention to either shape, color, or speed. They found that selective attention to each stimulus attribute enhanced activity in a region of visual cortex that was not stimulated by attention to the other two attributes. These results support the idea that attention to a particular stimulus attribute enhances activity in the extrastriate visual area specialized for processing that attribute.

Given this modular view of visual processing, we might have expected to find a single area or pathway that carried both sensory and extraretinal signals for direction matching. However,
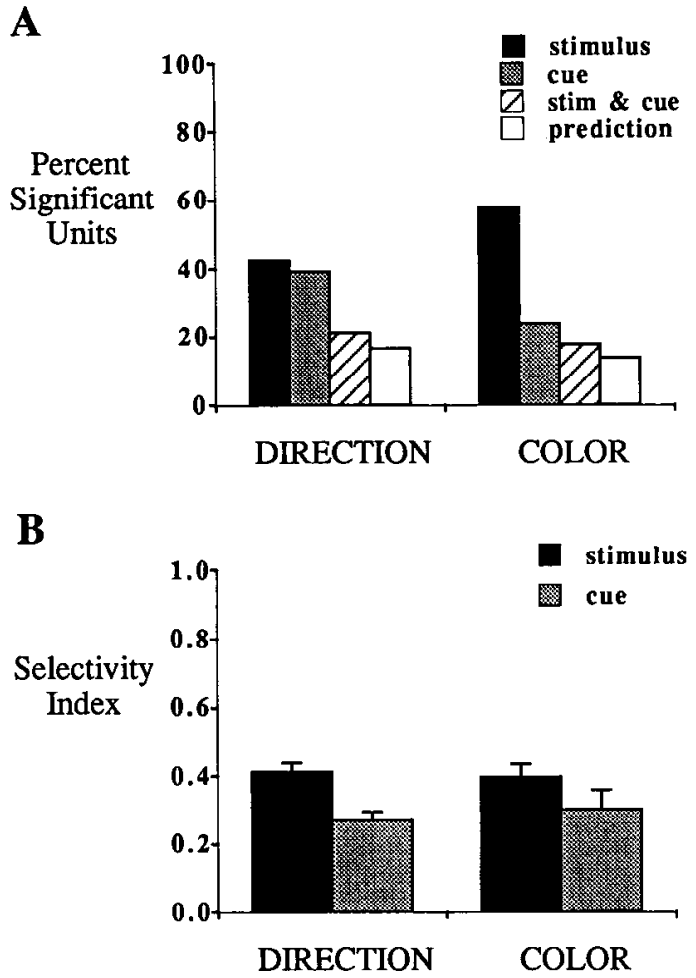

Figure 12. Results for all V4 neurons of a two-way ANOVA used to test the reliability of cue and stimulus direction signals. $A$, Percentage of neurons that reached significance at the $p \leq 0.05$ level for stimulus direction (black bars) and cue direction (gray bars). The hatched bars indicate the percentage of units that reached significance for both stimulus and cue direction along with the proportion of such neurons that would be expected if the properties of stimulus and cue direction selectivity were distributed independently among the population of neurons. $B$, Average cue and stimulus direction selectivity indices (mean $\pm \mathrm{SE}$ ) for units that had significant ANOVAs.

our results suggest that the sensory and cognitive signals for direction matching are distributed among visual areas spanning different cortical pathways (see Regan et al., 1992). When a moving stimulus is presented, it activates direction-selective units in many visual areas, including V4 and MT. Almost all of the cells in MT, and many in V4, have conventional direction selectivity, which presumably contributes to a representation of the motion in the current retinal stimulus. Other neurons, mostly in V4, but a few in parietal cortex, are activated by the current visual stimulus, but the magnitude of their response is determined by the direction of the remembered cue. These results suggest that the parietal pathway is responsible for encoding the direction of the current stimulus while the temporal pathway provides the behavioral context required for identifying the matching stimulus. This view is roughly consistent with the present findings, although the division of labor between the two pathways is not absolute; both may contribute to the representation of the current direction and of the remembered direction, to greater or lesser degrees.

\section{The nature of extraretinal signals in short-term memory tasks}

Several studies have used the match-to-sample paradigm to explore extraretinal signals in V4 (Haenny et al., 1988; Maunsell et al., 1991), anterior inferotemporal (IT) cortex (Fuster and Jervey, 1981; Miyashita and Chang, 1988; Miller et al., 1993), and now in parietal cortex. Fuster and Jervey (1981) and Mi- 
yashita and Chang (1988) reported elevated activity levels during the delay period following the presentation of the cue. In some cells, this delay activity was proportional to the sensory response elicited when the cue was presented, as if these cells were retaining an explicit visual image of the cue. The usefulness of visual imagery as a storage mechanism is diminished when one or more intervening stimuli are presented between the cue and match because the intervening stimuli may interfere with the stored image if both are represented by activity in the same set of cells. Miller et al. (1993) used a paradigm in which several stimuli were presented between the cue and match. They found that after the first intervening nonmatch, delay activity generally returned to baseline levels, in effect "erasing" the stored visual image. These authors found that many AIT neurons responded differentially to match and nonmatch conditions, over a wide range of stimuli and with up to five intervening nonmatches on a given trial. Their results suggest that memory signals in temporal cortex are not tied to particular stimuli, but are more abstract.

In the present sample of parietal and V4 neurons, we saw no significant modulation of activity in the delay period and few cells with significantly different match/nonmatch responses. The most striking effect we saw was the cue-dependent modulation of responses to stimuli presented after the cue, as previously reported for V4 neurons (Haenny et al., 1988; Maunsell et al., 1991). This kind of extraretinal signal has been found in area V4 for a range of stimulus attributes: motion, color, visual orientation, and tactile orientation. Single neurons may show this type of signal for more than one stimulus dimension (e.g., motion and color, visual and tactile orientation), and these effects are not predicated on the neuron's sensory selectivity. This suggests that there is something in the general nature of the task that evokes extraretinal signals in V4. [In contrast, the weakness or absence of extraretinal signals in MT does not appear to be task dependent. Newsome et al. (1988) found extraretinal signals were very weak in MT when the animals were trained to do smooth pursuit, a behavior in which the parietal pathway has been strongly implicated.] The present results, along with those of Miller and co-workers, suggest that extraretinal signals in the temporal visual pathway may be rather abstract and not specific to a particular stimulus attribute or even a particular sensory modality.

There are distinct advantages of an abstract versus literal representation of behaviorally relevant stimuli. It is difficult to maintain an explicit visual picture of what one is trying to remember when faced with a continuous stream of visual inputs that require processing. However, short-term memory tasks may be simplified by using a recoding strategy that reduces the item(s) to be remembered to abstract symbols, which are stored in a representation that is relatively insensitive to incoming stimuli. For humans, a natural way to do this is to use a verbal representation, replacing each stimulus by a name (e.g. "up," "down," "left," "right"). The matching operation may then be carried out entirely at the level of the verbal representation, and is thus freed from the "tyranny of the senses" (Teuber, 1967). By bringing together a variety of stimulus attributes and transforming the related sensory signals into a more abstract representation, the output of V4 might represent the rudiments of a visual code for object recognition.

The construction of an abstract representation is likely to occur in several stages of processing in V4 and IT cortex. By considering our results in the context of similar work done in
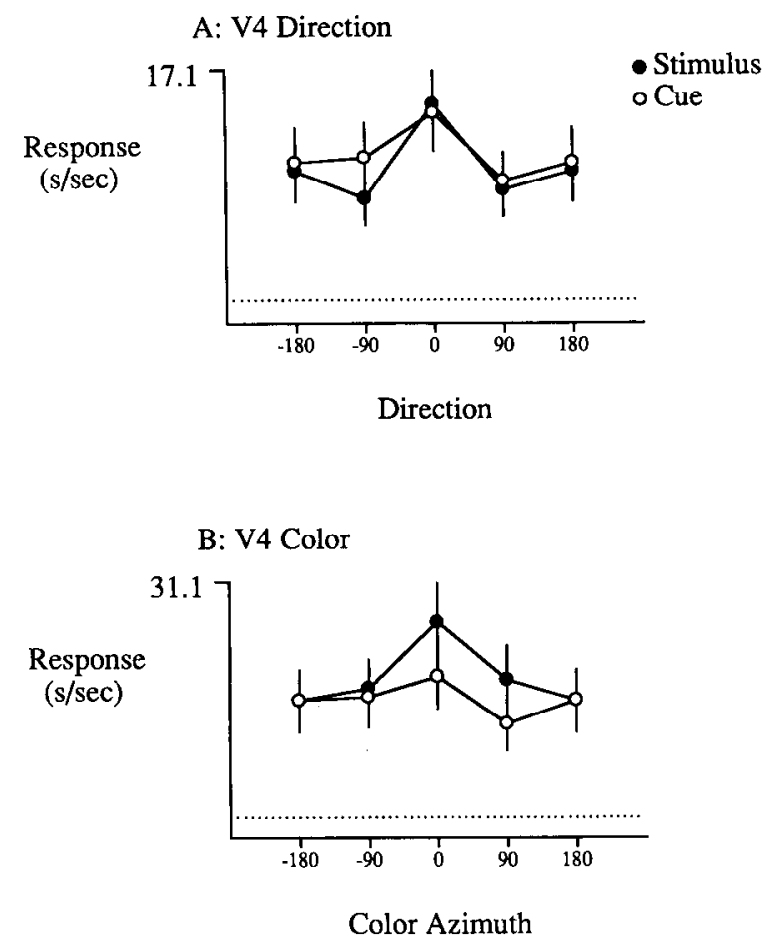

Figure 13. "Tuning curves" constructed by averaging the raw responses of all V4 units found to have statistically significant stimulus or cue selectivity. For each unit and condition (i.e., stimulus direction or color, cue direction or color) the responses were shifted so that the preferred responses are aligned. The horizontal axis indicates direction of motion relative to the preferred direction. The vertical axis is the average response in terms of spikes/sec. The error bars represent \pm 1 SEM. The dotted lines are the average spontaneous activity. The term "color azimuth" refers to the azimuth in Cardinal Direction color space (Derrington et al., 1984) relative to the preferred color.

inferotemporal cortex (Miller et al., 1993), we may speculate as to the nature of two of these stages. As mentioned above, Miller and co-workers reported on the responses of anterior IT neurons during a match-to-sample task similar in design to that used in the present study, but employing a vastly larger repertoire of (nonmoving) stimuli. While the present study is concerned with the ability of cells to identify stimulus and cue direction, that of Miller and co-workers was concerned with cells' ability to classify any stimulus as matching or nonmatching. They found that $48 \%$ of neurons in IT gave significantly different responses to matching versus nonmatching stimuli, and that the average reliability of those cells was about $60-65 \%$ based on an analysis similar to the ROC measure used in the present study. They presented a model in which the monkey's behavioral decision was based on the difference in response between a pool of sensory neurons, which are not modulated by behavioral context, and a pool of adaptive neurons, that is, cells that discriminate between matching and nonmatching stimulus conditions. However, their model gave no account of a mechanism that could give rise to the responses of adaptive neurons in IT. Here, we would like to extend the model of Miller and co-workers by proposing that the responses of adaptive neurons in IT might be due to a mechanism that computes the difference in activity between stimulus-selective neurons and cue-selective neurons in V4. Specifically, when a stimulus is shown during a trial, for example, a pattern of dots moving upward, this activates direction-selective neurons that encode a representation of stim- 
ulus direction. The stimulus also activates neurons selective for cue direction, but the responses of these cells represent the direction of the cue presented at the beginning of the trial, independently of the direction of the current stimulus. If one could simultaneously record the response of a cue cell and a stimulus cell that had the same preferred direction, then the condition in which both cells are maximally activated would be a matching condition. If one takes the difference in response of pairs of stimulus and cue cells, and provides that as an input to the adaptive neurons in IT, then the response of the IT cells will generally be less when the stimulus and cue match than when they do not match. This is in keeping with the finding of Miller and co-workers that the responses of IT neurons are generally suppressed for the matching condition relative to the nonmatching conditions.

\section{Direction selectivity in parietal and temporal visual areas: a unique motion pathway?}

One of the basic functional distinctions between the parietal and temporal visual pathways was set forth by Zeki (1978), who found that almost all of the cells in area MT were directionally selective, as opposed to virtually none $(<5 \%)$ in V4. It was largely on the basis of this report that MT came to be considered by some as "the motion area", and V4, with $54 \%$ color opponent neurons (as reported by Zeki, 1978; but see Schein and Desimone, 1990), as "the color area." The extreme direction selectivity of MT neurons has been confirmed by many subsequent studies, notably that of Newsome et al. (1989), in which single neurons in MT were found to be as reliable as the monkeys themselves in discriminating opposite directions of motion.

Zeki (1978) used a strict criterion to classify cells as direction selective, requiring that they have no response to the null direction. Other studies, using different criteria, have found a greater degree of direction selectivity in V4. Desimone and Schein (1987) found that about $13 \%$ of the cells in V4 responded to bars moving in their preferred direction at least five times as strongly as to bars moving in the null direction. About $30 \%$ of V4 neurons had preferred:null ratios greater than $2: 1$, which is roughly the same proportion reported by Mountcastle et al. (1987). In the present study, we found 33\% of V4 neurons with direction selectivity at the 2:1 level. By comparison, about $44 \%$ of V4 neurons could be classified as color selective using a similar criterion (Schein and Desimone, 1990). It should be noted that we didn't necessarily test neurons along their best axis of motion, but always used a stimulus set comprising the same four cardinal directions. It is therefore likely that we systematically underestimated the direction selectivity of neurons in all areas.

On the basis of these comparisons, it would appear that the role of V4 in motion processing might have been underestimated, while its role in color vision has been somewhat exaggerated. It is probably closer to the truth to say that, in terms of stimulus selectivity, V4 is less specialized than MT, but a substantial number of V4 neurons are capable of conveying reliable information about direction of motion. While it is clear that response properties in MT and V4 are polarized with respect to the motion versus color/form distinction, the functional consequences of this division are not as clear. The ability to discriminate the direction and speed of moving random dots survives ablation of MT and MST to a moderate degree (Newsome and Paré, 1988; Pasternak et al., 1991; Pasternak and Merigan, in press), suggesting that the rest of the visual system can com- pensate for lesions of the motion pathway. Likewise, lesions of $\mathrm{V} 4$ result in limited disruption of color vision (Heywood et al., 1992).

It may be inappropriate to think of motion processing as a single visual capability associated with a unique cortical pathway. Direction selectivity is widespread in visual cortex and is likely to contribute to many types of behavior. The degree to which the parietal and temporal pathways are involved in motion processing may be task specific. Motion that is produced by movements of the observer or by whole-body movements of rigid objects obeys certain computational constraints that seem to correspond well with response properties of neurons in parietal cortex. Motion that is thus imposed on objects in the environment may be thought of as extrinsic to those objects. On the other hand, motion may be thought of as intrinsic when it actually defines the form, or is used for identification of the object. Intrinsic attributes are, by definition, those that are related to object identity and would therefore be associated with the temporal pathway. Intrinsic motion may obey a much different and less well-defined set of computational constraints, particularly if it is the complex, nonrigid movements of animals (Hoffman and Flinchbaugh, 1982).

There is good evidence that the parietal pathway is involved in extrinsic motion tasks such as represcnting target motion for smooth pursuit eye movements (Komatsu and Wurtz, 1988a,b, 1989; Newsome et al., 1988) and analyzing optic flow patterns (Saito et al., 1986; Duffy and Wurtz, 1991). So far, there is no evidence that the temporal pathway is involved in either of these tasks, although the issue has not been carefully studied. Newsome et al. (1988) found that extraretinal signals in area MST during pursuit were generally as strong as the visual response to the pursuit target. For direction matching, we found that extraretinal signals in MST are much weaker than visual responses. Thus, the relative strength of extraretinal signals in any particular area is likely to be task specific.

There is some evidence that the temporal pathway is involved in processing intrinsic motion. Neurons that respond to motiondefined form have recently been found in V4 (Logothetis and Charles, 1990) and IT cortex (Sáry et al., 1993). There is also evidence that some neurons in inferotemporal cortex respond selectively to particular kinds of hand movements (Perrett et al., 1989). It may turn out that the temporal pathway has a primary role in the ability to recognize certain patterns of motion as the movements of animals (biological motion), to identify animals on the basis of their movements, and to infer intentionality, social cues, and other types of visual communication from motion information (Brothers et al., 1990). It is possible that motion-defined-form processing, direction matching, and other motion-based identification tasks share the same pathway and that none of these rely on the sensory processing of motion by the parietal pathway. Rather, the degree of conventional direction selectivity seen in V4 may be sufficient for these tasks. Against this view is the finding by Regan et al. (1992) that humans with lesions in the white matter underlying parietotemporal cortex were impaired in their ability to perceive motiondefined forms. Regan and co-workers proposed that motiondefined form recognition depends on interconnections between the motion and color/form pathways. This proposal warrants further investigation. At present it is an open question whether there is any task or function that involves both pathways in such a manner that their contributions must be combined before a decision or movement can be made. 


\section{References}

Albright TD (1984) Direction and orientation selectivity of neurons in visual area MT of the macaque. J Neurophysiol 52:1106-1130.

Alpern M (1972) Eye movements. In: Handbook of sensory physiology (Jameson D, Hurvich LM, eds), pp 303-330. New York: Springer.

Andersen RA (1987) Inferior parietal lobule function in spatial perception and visuomotor integration. In: Handbook of physiology, pp 483-518. Baltimore: Williams and Wilkins.

Andersen RA, Mountcastle VB (1983) The influence of the angle of gaze upon the excitability of the light-sensitive neurons of the posterior parietal cortex. J Neurosci 3:532-548.

Andersen RA, Bracewell RM, Barash S, Gnadt JW, Fogassi L (1990) Eye position effects on visual, memory, and saccade-related activity in areas LIP and 7a of macaque. J Neurosci 10:1176-1196.

Britten KH, Shadlen MN, Newsome WT, Movshon JA (1992) The analysis of visual motion: a comparison of neuronal and psychophysical performance. J Neurosci 12:4745-4765.

Brothers L, Ring B, Kling A (1990) Response of neurons in the macaque amygdala to complex social stimuli. Behav Brain Res 41:199213.

Corbetta M, Miezin FM, Dobmeyer S, Shulman GL, Petersen SE (1990) Attentional modulation of neural processing of shape, color, and velocity in humans. Science 248:1556-1559.

Corbetta M, Miezin FM, Dobmeyer S, Shulman GL, Petersen SE (1991) Selective and divided attention during visual discriminations of shape, color, and speed: functional anatomy by positron emission tomography. J Neurosci 11:2383-2402.

Dean P (1976) Effects of inferotemporal lesions on the bchavior of monkeys. Psychol Bull 83:41-71.

Derrington AM, Krauskopf J, Lennie PL (1984) Chromatic mechanisms in lateral geniculate nucleus of macaque. J Physiol (Lond) 357: 241-265.

Desimone R, Schein SJ (1987) Visual properties of neurons in area V4 of the macaque: sensitivity to stimulus form. J Neurophysiol 57: 835-868.

Desimone R, Schein SJ, Moran J, Ungerleider LG (1985) Contour, color and shape analysis beyond the striate cortex. Vision Res 25 : $441-452$.

Duffy CJ, Wurtz RH (1991) Sensitivity of MST neurons to optic flow stimuli. I. A continuum of response selectivity to large-field stimuli. J Neurophysiol 65:1329-1345.

Duhamel JR, Colby CL, Goldberg ME (1992) The updating of the representation of visual space in parietal cortex by intended eye movements. Science 255:90-92.

Felleman DJ, Van Essen DC (1991) Distributed hierarchical processing in the primate cerebral cortex. Cereb Cortex 1:1-47.

Ferrera VP, Maunsell JHR (1992) Extraretinal signals in relation to parallel pathways in macaque visual cortex. Soc Neurosci Abstr 18: 592.

Fuster JM (1990) Inferotemporal units in selective visual attention and short-term memory. J Neurophysiol 64:681-697.

Fuster JM, Jervey JP (1981) Inferotemporal neurons distinguish and retain behaviorally relevant features of visual stimuli. Science 212 : 952-955.

Gallyas F (1979) Silver staining of myelin by means of physical development. Neurol Res 1:203-209.

Goodale MA, Milner AD (1992) Separate pathways for perception and action. Trends Neurosci 15:20-25.

Gross CG, Rocha-Miranda CE, Bender DB (1972) Visual properties of neurons in inferotemporal cortex of the macaque. J Neurophysiol 35:96-111.

Haenny PE, Maunsell JHR, Schiller PH (1988) State dependent activity in monkey visual cortex. II. Extraretinal factors in V4. Exp Brain Res 69:245-259

Heywood CA, Gadotti A, Cowey A (1992) Cortical area V4 and its role in the perception of color. J Neurosci 12:4056-4065.

Hoffman DD, Flinchbaugh BE (1982) The interpretation of biological motion. Biol Cybern 42:195-204.

Judge SJ, Richmond BJ, Chu FC (1980) Implantation of magnetic search coils for measurement of eye position: an improved method. Vision Res 20:535-538.

Komatsu H, Wurtz RH (1988a) Relation of cortical areas MT and MST to pursuit eye movements. I. Localization and visual properties of neurons. J Neurophysiol 60:621-644.

Komatsu H, Wurtz RH (1988b) Relation of cortical areas MT and
MST to pursuit eye movements. III. Interaction with full-field visual stimulation. J Neurophysiol 60:621-644.

Komatsu H, Wurtz RH (1989) Modulation of pursuit eye movements by stimulation of cortical areas MT and MST. J Neurophysiol 62: $31-47$.

Logothctis NK, Charles ER (1990) V4 responses to gratings defined by random dot motion. Invest Ophthalmol Vis Sci [Suppl] 31:90.

Maunsell JHR, Van Essen DC (1983) Functional properties of neurons in the middle temporal visual area (MT) of the macaque monkey: $\mathrm{I}$. Selectivity for stimulus direction, speed and orientation. J Neurophysiol 49:1127-1147.

Maunsell JHR, Sclar G, Nealey TA, DePriest DD (1991) Extraretinal representations in area V4 in the macaque monkey. Vis Neurosci $7: 561-573$

Merigan WH, Byrne CE, Maunsell JHR (1991) Does primate motion perception depend on the magnocellular pathway? J Neurosci 11: 3422-3429.

Miller EK, Li L, Desimone R (1993) Activity of neurons in anterior inferior temporal cortex curing a short-term memory task. J Neurosci 13:1460-1478.

Miyashita Y, Chang HS (1988) Neuronal correlate of pictorial shortterm memory in the primate temporal cortex. Nature 331:68-70.

Moran J, Desimone R (1985) Selective attention gates visual processing in the extrastriate cortex. Science 229:782-784.

Mountcastle VB, Motter BC, Steinmetz MA, Sestokas AK (1987) Common and differential effects of attentive fixation on the excitability of parietal and prestriate (V4) cortical neurons in the macaque monkey. J Neurosci 7:2239-2255.

Newsome WT, Paré EB (1988) A selective impairment of motion perception following lesions of the middle temporal visual area (MT). J Neurosci 8:2201-2211.

Newsome WT, Wurtz RH, Komatsu H (1988) Relation of cortical areas MT and MST to pursuit eye movements. II. Differentiation of retinal from extraretinal inputs. J Neurophysiol 60:604-620.

Newsome WT, Britten KH, Movshon JA (1989) Neuronal correlates of a perceptual decision. Nature 341:52-54.

Pasternak T, Merigan WH (in press) Motion perception following lesions of the superior temporal sulcus of the monkey. Cereb Cortex, in press.

Pasternak T, Maunsell JHR, Polashenski W, Merigan WH (1991) Deficits in global motion perception after MT/MST lesions in a macaque. Invest Ophthalmol Vis Sci [Suppl] 32:824.

Perrett DI, Harries MH, Bevan R, Thomas S, Benson PJ, Mistlin AJ, Chitty AJ, Hietanen JK, Ortega JE (1989) Frameworks of analysis for the neural representation of animate objects and actions. J Exp Biol 146:87-113.

Regan D, Giaschi D, Sharpe JA, Hong XH (1992) Visual processing of motion-defined form: selective failure in patients with parietotemporal lesions. J Neurosci 12:2198-2210.

Remmel RS (1984) An inexpensive eye movement monitor using the scleral search coil technique. IEEE Trans Biomed Eng 31:388-390.

Richmond BJ, Optican LM, Podell M, Spitzer H (1987) Temporal encoding of two-dimensional patterns by single units in primate inferior temporal cortex. I. Response characteristics. J Neurophysiol 57:132-146.

Robinson DA (1963) A method of measuring eye movements using a scleral search coil in a magnetic field. IEEE Trans Biomed Eng 101: $131-145$.

Saito H, Yukie M, Tanaka M, Hikosaka K, Fukada Y, Iwai E (1986) Integration of direction signals of image motion in the superior temporal sulcus of the macaque monkey. J Neurosci 6:145-157.

Salzman CD, Murasugi CM, Britten KH, Newsome WT (1992) Microstimulation in visual area MT: effects on direction discrimination performance. J Neurosci 12:2331-2355.

Sáry G, Vogels R, Orban GA (1993) Cue-invariant shape selectivity of macaque inferior temporal neurons. Science 260:995-997.

Schein SJ, Desimone R (1990) Spectral properties of V4 neurons in the macaque. J Neurosci 10:3369-3389.

Schiller PH, Lee K (1991) The role of the primate extrastriate area $\mathrm{V} 4$ in vision. Science 251:1251-1253.

Spitzer H, Desimone R, Moran J (1988) Increased attention enhances both behavioral and neuronal performance. Science 240:338-340.

Steinmetz MA, Connor CE, MacLeod KM (1992) Focal spatial attention suppresses responses of visual neurons in monkey posterior parietal cortex. Soc Neurosci Abstr 18:148.

Szabo J, Cowan WM (1984) A stereotaxic atlas of the brain of the 
cynomolgus monkey (Macaca fascicularis). J Comp Neurol 222:265300.

Tanaka M, Weber H, Creutzfeldt OD (1986) Visual properties and spatial distribution of neurones in the visual association area on the prelunate gyrus of the awake monkey. Exp Brain Res 65:11-37.

Teuber HL (1967) Lacunae and research approaches to them. In: Brain mechanisms underlying speech and language (Millikan $\mathrm{CH}$, Darley FL, eds), pp 204-216. New York: Grune and Stratton.

Tolhurst DJ, Movshon JA, Dean AF (1983) The statistical reliability of signals in single neurons in cat and monkey visual cortex. Vision Res 23:775-785.

Triesman AM (1988) Features and objects: the fourteenth Bartlett memorial lecture. Q J Exp Psychol 40A:201-237.

Ungerlcider LG, Mishkin M (1982) Two cortical visual systems. In:
Analysis of visual behavior (Ingle DJ, Goodale MA, Mansfield RJW, eds), pp 549-586. Cambridge, MA: MIT Press.

Van Essen DC, Maunsell JHR, Bixby JL (1981) The middle temporal visual area in the macaque: myeloarchitecture, connections, functional properties, and topographic organization. J Comp Neurol 199: 293-326.

Van Essen DC, Anderson CH, Felleman DJ (1992) Information processing in the primate visual system: an integrated systems perspective. Science 255:419-423.

Wolbarsht ML, McNichol EG, Wagner HG (1960) Glass insulated platinum microelectrode. Science 132:1309-1310.

Zeki SM (1978) Uniformity and diversity of structure and function in rhesus monkey prestriate visual cortex. J Physiol (Lond) 277:273290. 